\title{
Signal Competition in Dynamic Visual Environments: Relative Conspicuousness of Social Displays in the Jacky Dragon (Amphibolurus muricatus)
}

\author{
Kevin L. Woo \\ Department of Natural Sciences, School of Science, Mathematics, \& Technology, State University of New York, Empire State \\ College \\ Corresponding author (Email: Kevin.Woo@esc.edu)
}

Citation - Woo, K. L. (2021). Signal competition in dynamic visual environments: Relative conspicuousness of social displays in the Jacky dragon (Amphibolurus muricatus). Animal Behavior and Cognition, 8(3), 415-445. https://doi.org/10.26451/abc.08.03.07.2021

\begin{abstract}
Selection for conspicuousness has been an important force on visual signal design. Although signal efficacy has been extensively studied in acoustic systems, few studies have examined this attribute in dynamic visual signals. Here, I simulated signal competition between Jacky lizards (Amphibolurus muricatus) by presenting the motor patterns (tail-flick, push-up body rock, and slow arm wave) in isolation that are typically used in social communication. Phase 1 used four digital video playback systems to present simultaneous animated display combinations on opposing monitors to a subject that was situated in the middle, and measured orientation towards the monitors and latency to respond. Phase 2 maintained the same set-up and simultaneous display combinations, but tested signal conspicuousness across three levels of visual noise (calm, typical, and windy) simulated by the movement of windblown vegetation in the background. The results suggest that the most conspicuous visual display is the tailflick, followed by the push-up body rock, and the slow arm wave is the least conspicuous. Moreover, this relationship is robust across the full range of environmental wind conditions. No significant side biases in orientation to displays were detected, which suggested no lateralization in perceptual processes. Jacky lizard display motor patterns which address distinct functional requirements: the tail flick is an ideal alerting component, with high efficacy over a range of signaling conditions. The push-up body rock, which is used only in aggressive displays, has a more restricted range, and the submissive slow arm wave is likely designed to appease nearby dominant males.
\end{abstract}

Keywords - Jacky dragon, Amphibolurus muricatus, Video playback, Animation, Signal competition, Conspicuousness, Visual noise

To be effective, signals need to be received by the intended receiver and this is often not simple. Signals in nature are subject to competition from the signals of other individuals, such as when two conspecifics produce the same type of signal in a disputed territory. Direct signal competition in acoustic signaling has been widely studied in frogs (Bosch et al., 2000), crickets (Bertram, 2004), grasshoppers (Minckley et al., 1995, fish (Thorson \& Fine, 2002), birds (Brémond, 1978), and bats (Ulanovsky et al., 2004). Signals in competition may be specifically designed to interfere with the signals of others, such as in the ghost knifefish (Apteronotus leptorhynchus) that use an electrical discharge to disrupt communication (Tallarovic \& Zakon, 2005), or to synchronize with the signals of others, as in the firefly (Lampyridae) in which the bioluminescence display behavior is used to maximize local attention and minimize predation risk in their abundance (Allard, 1935; Buck, 1938, 1988; Morrison, 1929). 
Studies that have examined the nature of direct visual signal competition typically test the function of coloration in sexual selection (Andersson, 1994; López et al., 2004) or territoriality (O'Connor et al., 1999). For example, in a staged contest between threespine sticklebacks (Gasterosteus aculeatus), live males were shown three different videotaped images of rivals with one of three altered colorations: bright, moderate, and dull (Rowland et al., 1995). Indicative of nuptial coloration, live males were found to attack moderately colored males most often, as a trade-off between perceived opponent aggression and fear (Rowland et al., 1995). Additional male-male competition studies have provided further empirical evidence for the relative salience of visual signals during competitive interactions, such as in the threespine stickleback (G. aculeatus; Baube et al., 1995) or fighting fish (Betta splendens; Allen \& Nicolleto, 1997), but few have thoroughly explored competition between movement-based displays. The studies that have examined the detection of postural displays during competitive situations have focused on interactions mainly between two individuals (i.e., male-male competition, Jenssen et al., 2005), between two individuals with a single spectator (i.e., male-male competition and female choice, DeCourcy \& Jenssen, 1994; Tarof et al., 2005), or movements that are not stereotyped displays (Walls \& Semlitisch, 1991). In contrast, studies that have examined direct male-male competition with an additional male spectator, aside from eavesdropping studies (Peake, 2005), have had limited exploration.

As signals are produced in natural settings, selection for conspicuousness is heavily constrained by the influence of environmental noise. In the acoustic system, environmental noise may be generated by the signals of others (Gerhardt \& Klump, 1988), and the reverberation and the masking effect from wind that is blown across vegetation (Ryan 1986; Wiley \& Richards, 1978). However, environmental noise consistently interferes with other communication modalities, such as vibratory (e.g., thumping in whitelipped frogs, Leptodactylus albilabris, Lewis et al., 2001), chemosensory (e.g., urine detection in American lobsters, Homarus americanus, Atema, 1995), and electrical (e.g., pulses from weakly electric fish, Gymnotus carapo, Watson \& Bastian, 1979) signals. In the visual system, the aggressive dewlap display of Anolis lizards was found to be conspicuous against the movement of vegetation (Fleishman, 1986; Fleishman \& Persons, 2001). Thus, ambient vegetation as the primary source of environmental noise has consistently been identified as a selective force on the evolution of conspicuous movement-based visual signals (Fleishman, 1988a, b, 1992; Persons et al., 1999).

If the same signal is presented by two conspecifics, there is the potential that a third individual may be in range of the visual display. The response by the eavesdropping individual to attenuate one signaler one over the other may suggest a side bias that indicates hemispheric lateralized function during social interactions (Marx, 1983). There is sufficient evidence to suggest that a similar pattern of lateralized behavior exists in humans (Fox, 1991), non-human primates (Rogers \& Kaplan, 1996), birds (Hoffman et al., 2006), fish (Cantalupo et al., 1996; Miklósi et al., 1998; Sovrano, 2004), and lizards (Deckel, 1995). For example, displays in Anolis lizards have been observed and performed in view of the left eye, and therefore mediated by the right cerebral hemisphere (Deckel, 1995). Predator avoidance responses from three species of toads (i.e., Bufo bufo, B. viridis, and B. marinus) also suggest that flight responses are dependent upon the left monocular field and mediated by the right hemisphere of the brain (Lippolos et al., 2002). However, this is not true for all reptile species. For example, in the alpine newt (Triturus alpestris), there simply appears to be no direct evidence for hemispheric lateralization (Marzona \& Giacoma, 2002).

Jacky dragons (Amphibolurus muricatus) are an Australian agamid species found in complex habitat of coastal heathland, rocky ridges, and sclerophyll forests (Harlow \& Taylor, 2000). They exchange stereotyped displays that are used during social communication to mediate contests of territoriality and mate selection (Carpenter et al., 1970; Carpenter \& Fergusson, 1977; Peters \& Ord, 2003; Van Dyk \& Evans, 2007). Three discrete displays are produced during social interactions including an assertive tailflick (Peters \& Evans, 2003b), aggressive push-up body rock (Gibbons, 1979), and submissive slow arm wave (Ord \& Evans, 2002). Across the many studies that have examined visual signal conspicuousness and recognition, all Jacky dragon social displays have been shown to be highly conspicuous on their own when presented in staged encounters between video or animated stimuli, and live individuals (Ord, Peters, et al., 2002; Peters \& Evans, 2003a, b; Woo \& Rieucau, 2012, 2013, 2015). 
I tested whether the visual displays within the Jacky dragon repertoire are capable of eliciting responses from eavesdropping individuals when they are in competition with each other. For example, this likely occurs when two individuals are signaling from adjacent territories. As with signal exchanges in situ, a third individual or observer would hence be subjected to these displays at the same time. I initially presented Jacky dragons with all possible combinations of three social signals that were digitally manipulated and subsequently embedded within a similar natural background. I then tested relative conspicuousness to visual displays to determine whether these signals were affected by variation in wind conditions. To alter environmental conditions, the animated stimuli of social displays were presented with the simulated movement of windblown vegetation (i.e., calm, typical, and windy) in the background. In addition, I also tested for the likelihood of potential sides bias in response to the same competing displays.

\section{Method}

\section{Subjects}

Six male Jacky dragons, captured from Lane Cove National Park in Sydney, Australia (NSW License No. S11024), were housed individually in identical glass enclosures in captive facilities at Macquarie University (AEC Protocol \# 2006/012). Subjects were visually isolated from one another. Enclosures measured $60(\mathrm{H}) \times 60(\mathrm{~L}) \times 60(\mathrm{~W}) \mathrm{cm}$ and contained Sydney sand substrate, native leaf litter, and natural perches that consisted of severed branches. Each enclosure was covered with a wire mesh to allow for daily spraying to maintain humidity and to prevent the subject from escaping. All enclosures were also placed on movable trolleys to allow them to be positioned into the testing area without handling the subject. Subjects were maintained on an artificial 12L:12D light cycle during a simulated summer season. During this time, the lights were switched on at 07:00 with heat lamps (125 W Spotone, Phillips, NSW, Australia) on from 08:00-18:00, and UV bulbs (300W Ultra-Vitalux, Osram, NSW, Australia) from 07:4508:00. Subjects were fed twice a week and were provided with either crickets (Acheta domesticus) or mealworms (Tenebrio molitor) from Pisces Enterprises, LTD (Brisbane, Australia). The invertebrates were dusted in vitamin supplements (RepCal, Victoria, Australia), and water was provided ad libitum. I maintained the room at a stable temperature of $25 \pm 3^{\circ} \mathrm{C}$ with minor daily fluctuations in temperature and humidity. Subjects were routinely wormed using Ivermectin and each enclosure was routinely cleaned. After the completion of the study, all subjects were released near the point of original capture.

\section{Equipment}

Four identical video playback systems were used for displaying all stimuli. The video monitor for each system was placed adjacent to the four sides of the testing enclosure to face the subject (Figure 1). Each video playback system consisted of an iMac (Apple Inc., Cupertino, CA, USA) running Final Cut Pro 3 (Apple Inc., Cupertino, CA, USA). A 250Gb LaCie d2 hard drive (Hillsboro, Oregon, USA) was attached to each iMac and stored the stimuli. At the onset of the stimuli presentation, a digital video was presented and an audio tone was generated to mark the event, but this audio tone was only audible upon video review for scoring. The video/audio output from the iMac was then converted to an analog signal using a Canopus® ADVC110 (Melbourne, Victoria, Australia). The video signal from all four systems was displayed on a color Sony Trintron playback monitor (Model Nos. PVM-14N5A/PVM-14M2A/PVM-14L2, Sony Corporation, Tokyo, Japan).

All trials were recorded with a Canon (Model No. MV650i, Canon Inc., Tokyo, Japan) digital camcorder with $22 \mathrm{X}$ optical zoom that was mounted to a stationary tripod (Gruppo Manfrotto®, Italy) and placed directly above the testing area. Video was recorded straight to VHS on a Sony videocassette recorder (Model No. SLV-EZ717AS, Sony Corporation, Tokyo, Japan), and responses were viewed on a color viewfinder (NEC, Serial No. 1892, Kanagawa, Japan). Video playback was adjusted for PAL-DV standard (5:1 compression; horizontal resolution 575 lines; 25 frames per second). All VHS tapes were converted to 
MPEG4 files using EvolutionTVTM v2.6 Digital Video Recorder (Miglia Technology LTD 2005) for later viewing when scoring responses.

\section{Figure 1}

Schematic Diagram of the Video Playback Apparatus and Stimulus Presentation Set-Up

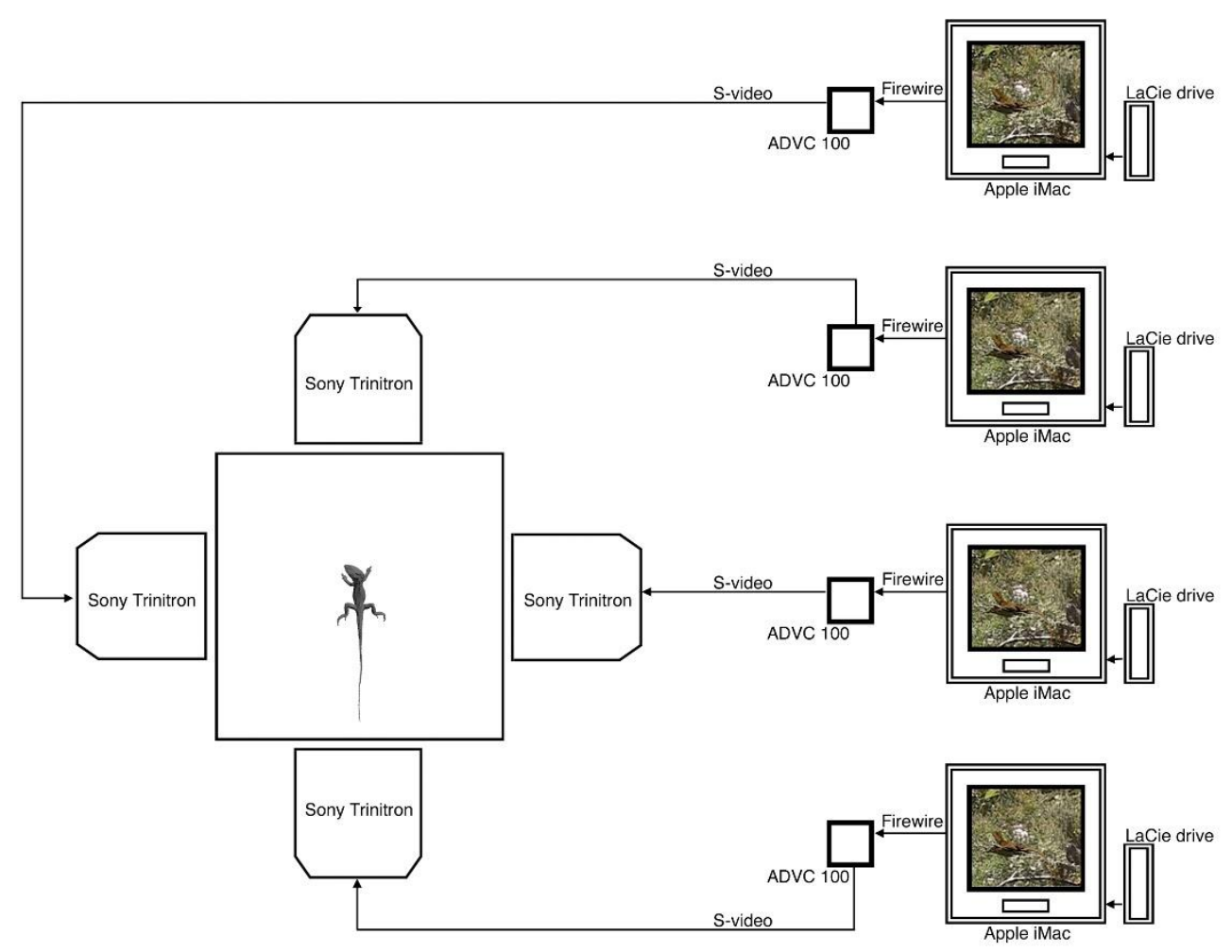

Note. The animation shown here is proportionally larger in the figure than during actual experimental trials to highlight the location of the computer-generated stimulus lizard in each monitor. In this staged trial, the focal individual has oriented to the left monitor, which is displaying a tail flick.

\section{Lizard Animation}

The use and application of video animated stimuli has been demonstrated to be an effective tool to study visual signals that are exchanged during social interactions (Chouinard-Thuly et al., 2017). Consequently, numerous validation studies have been conducted to ensure that computer-generated stimuli effectively elicit behavioral responses, such as in fish (Abaid et al., 2012; Gierszewski et al., 2017, 2018; Müller et al., 2017; Qin et al., 2014; Roberts et al., 2019), lizards (Ord \& Evans, 2002; Peters \& Evans, 2003b), spiders (Tedore \& Johnsen, 2013, 2015), and birds (Ware et al., 2017; Watanabe \& Troje, 2006). Here, I created a three-dimensional stimulus display model using Lightwave@ v8.3 (NewTek Inc., San Antonio, TX, USA) software. To provide context, a taxidermic model was used as the basis for the structure of the animation. I then scanned the taxidermic model with a Konica Minolta VI-9i (Konica Minolta Holdings, Inc., Japan) by New Dawn ${ }^{\circledR}$ (Bexley North, NSW, Australia). The animation was transformed into a digital object using the Raindrop Geomagic $®$ (Raindrop Geomagic, Inc., Research Triangle Park, $\mathrm{NC}$, USA) software to acquire a single polygon mesh of 50,000 polygons.

The object was then imported into a readable format into Lightwave@ 3D v8.3 (NewTek Inc., San Antonio, TX, USA). In the Modeller program of Lightwave $(-)$ v8.3 (NewTek Inc., San Antonio, TX, USA), "skelegons" were created to allow for manipulation of the object within the three-dimensional plane. 
Skelegons act as pivotal and rotational joints to manipulate the object into assigned movements. The number of skelegons was proportional to the number of bones in a real jacky dragon. Skelegons were created from the head down to the tip of the tail, thereby lining cervical, thoracic, lumbar, and sacral vertebrae. Front and hind limbs were also created and fused to the skeletal structure. After the construction of the internal frame, the skelegons are uploaded into the Layout program of Lightwave $\odot$ v8.3 (NewTek Inc., San Antonio, TX, USA) to incorporate animation features such as morphology and movement. In the Layout program, the skelegons were then converted to fused "bones" that became the stable infrastructure of the object. In addition to bones, counter-weighting for object manipulation was created by adding weight shades. Weight shading designates the amount of movement by antagonistic body parts and restricts movements on other parts. These limitations prevent the object from unnaturally changing its morphological shape. To add texture, digital photographs (JPEG) of a live jacky dragon were taken from various angles at one meter away using a 12.8-megapixel Canon EOS 5D (Canon, Inc., Tokyo, Japan). Using Adobe Photoshop v3.0 (Adobe Inc., San Jose, CA, USA), each area of the Jacky dragon was layered together to create a frontal, orthogonal, dorsal, and ventral view of the animal. These sections were then matched to the morphological section on the lizard model using the UV mapping tool within the Modeller program. The sections were accordingly matched to provide an anatomically, morphologically, and texturally correct lizard animation model. Subsequently, the object was then transferred to the Layout program to construct stimuli sequences. A more technical description of the lizard animation is described in Woo (2007), and Woo and Rieucau (2008).

I recreated each stimulus to simulate Jacky dragon motor patterns using the process of "rotoscoping," which matches the stimulus movements to the changes in an actual sequence (Gatesy et al., 1999). Stimuli sequences were matched to a single tail-flick (TF), push-up body rock (PUBR), and slow arm wave (SAW), which were sampled from population typical displays and that were modeled on lizard motor patterns from archival video footage (Ord \& Evans, 2002; Van Dyk \& Evans, 2007; Woo \& Rieucau, 2015). In addition, one control (CON) stimulus was created as a still lizard. A population typical lizard display archive video was selected for each display. The video clip was exported to an image sequence using Apple Quicktime v7.0 (Apple Inc., Cupertino, CA, USA). When rotoscoping, the model was manipulated to match the changes in display that were presented on the background of the Layout program. Each display was rotoscoped frame-by-frame to exactly match the movement of the video. This process was done for each frame until the full sequence had been matched to a complete display.

\section{Animation Sequences}

All sequences were processed using Lightwave@ $\odot$ v8.3 (NewTek Inc., San Antonio, TX, USA). The animated lizard was scaled to be life-sized as viewed from three meters. Both the subject scaling and distance was selected based on the appropriate measures for scaling that continued to elicit responses from typical distances between individuals in the wild (Peters, 2013; Peters \& Allen, 2009; Peters et al., 2008). Each type of background was placed in the backdrop of each of the three display animation sequences (see Phases 1 and 2 for background descriptions). The total duration for each completed animation sequence was six minutes in length. The complete sequence encompassed two parts. First, the animated lizard was motionless for the first five minutes to allow subjects to habituate to the stimulus. Then, at the fifth minute, the animation would either display (TF, PUBR, or SAW) or remain motionless (CON). The sequence would then continue for an additional minute, with a motionless lizard on the perch, thereby completing the total six-min duration. In each stimulus sequence, the display only appeared once without repetition.

All sequences were rendered using Render Farm Commander v2.9.9 (RFC; Bruce Rayne®, Lalor Park, NSW, Australia). RFC allows for mass rendering of large numbers of sequences producing large number of individual frames. A six-min sequence produced 9000 sequential JPEG images at PAL-DV standard (e.g., 25 frames per s). Image sequences were then transformed into DV files using Apple Quicktime $^{\mathrm{TM}}$ v7.0. Exported DV video files were then imported into Final Cut Pro 3. In conjunction with the display at the fifth minute, a digital sound cue was imbedded into the sequence. The cue was recorded directly onto VHS but was not heard during testing. As an auditory marker, the cue also indicated when an 
event occurred for scoring behaviors. Sequences were then exported as Final Cut Pro movie files for playback.

\section{General Procedure}

Subjects were presented with all possible stimulus pair combinations of motor patterns and windblown vegetation (Table 1), each in a unique random order. All four monitors began with the exact same video, background of windblown vegetation, and perched lizard animation, yet only two opposing monitors would produce competing displays. The assignment of paired stimuli to monitors was random, but I also ensured that each stimulus pairing only appeared on opposite monitors. The randomization of presentation monitors was important so that the focal individual did not habituate to the task or a specific set of monitors. In this approach, the detection task is likely more difficult, as a display has an equal chance to appear on any two opposing monitors. When lizards made a response, head and body orientations to display sequences demonstrated an obvious directional choice, as orientation responses were therefore unambiguous.

Table 1

Stimulus Presentation Combinations for Phases 1 and 2

\begin{tabular}{lc|l}
\hline \multirow{2}{*}{ Display } & \multicolumn{1}{c}{ Phase 1 } & Phase 2 \\
\cline { 2 - 3 } & Display & Wind Condition \\
\hline \multirow{3}{*}{ Control (CON) } & CON & Calm, Typical, Windy \\
& TF & Calm, Typical, Windy \\
& PUBR & Calm, Typical, Windy \\
& SAW & Calm, Typical, Windy \\
\hline \multirow{3}{*}{ Tail-flick (TF) } & CON & Calm, Typical, Windy \\
& TF & Calm, Typical, Windy \\
& PUBR & Calm, Typical, Windy \\
Push-up body rock (PUBR) & SAW & Calm, Typical, Windy \\
& CON & Calm, Typical, Windy \\
& TF & Calm, Typical, Windy \\
& PUBR & Calm, Typical, Windy \\
Slow arm wave (SAW) & SAW & Calm, Typical, Windy \\
& CON & Calm, Typical, Windy \\
& TF & Calm, Typical, Windy \\
& PUBR & Calm, Typical, Windy \\
& SAW & Calm, Typical, Windy \\
\hline
\end{tabular}

The background for each stimulus was matched for wind condition (see Phase 2 for descriptions of varying vegetation movement by wind speed). On the remaining two monitors (e.g., non-stimulus displaying) that were adjacent to the opposite monitors intended for display, video of matching natural windblown vegetation that was the same as the background for motor pattern stimulus presentation was played. In the non-stimuli monitors, the video of background motion was identical to the intended opposing stimuli display monitors to demonstrate background consistency across all video sequences. However, in the videos for non-stimuli monitors, a motionless lizard animation, which was the same identical baseline animation, was also placed on the central perch of the viewing frame (see Figure 1). 


\section{Phase 1 - Signal Competition Across Constant Visual Noise}

For realistic dynamic environments, background vegetation was filmed at La Perouse National Park (see Peters \& Evans, 2007), which was a location consistent with known capture sites for jacky lizards. In Peters and Evans (2007), windblown vegetation was recorded, but the wind speed was not measured and environmental conditions were not manipulated. The variation of wind speed and direction of windblown vegetation was important for replicating a range of normal and likely conditions that lizards would experience. In addition to the typical movement of windblown vegetation, Peters and Evans (2007) elected to film this background scene on a bright, sunny day with no cloud cover in order to provide the maximum illumination on the vegetation. A stable perch was also centrally placed within the vegetation and the recording frame so that the lizard animation could be imbedded in the same location for every stimulus that was generated. For the current study, the same background video from Peters and Evans (2007) was used for all the stimuli in this phase to simulate an opponent in situ.

During this phase, each subject was presented with four trials per day over 16 days. Each subject was presented with 32 trials in each of two replicates, for a total of 64 trials per individual.

\section{Phase 2 - Signal Competition Across Variable Levels of Environmental Noise}

Unlike the background vegetation that was used in Phase 1, the background vegetation in Phase 2 was composed of large native Proteaceae (Banskia spp.) that was also consistent with vegetation in the natural habitat of the Jacky dragon, but video exemplars also included the variation of three natural wind conditions. To recreate an aspect of noise that was relative to natural environmental variation, I used a large industrial pedestal fan (Ebony Fans) to simulate varying wind conditions. Recordings were made during an extremely calm $(<0.25 \mathrm{~m} / \mathrm{s}$ wind speed) and sunny day. Using this technique provided a constant stream of airflow with minimal interaction with atmospheric wind (Woo \& Rieucau, 2013; Woo et al., 2009). Whereas background vegetation in Phase 1 was consistent to establish reliable orientation responses to the onset of a stimulus, here I manipulated the background vegetation by employing three varying wind conditions that were simulated based on meteorological data (Peters et al., 2008; Woo et al., 2009): calm $(1.40 \mathrm{~m} / \mathrm{s})$, typical $(2.72 \mathrm{~m} / \mathrm{s})$, and windy $(4.24 \mathrm{~m} / \mathrm{s})$. Wind speeds were measured using a Velocicalc ${ }^{\circledR}$ anemometer (Model No. 8345/8346, TSI Incorporated Shoreview, MN, USA). Wind speed recordings were taken before and after the filmed sequence to ensure consistency and to prevent any disruption to filming. To provide a stage for the animation, I constructed a wooden perch that was placed in the middle of the recorded frame. All sequences were filmed for six minutes. Background footage was converted to individual image sequences (JPEGs) using Apple Quicktime ${ }^{\mathrm{TM}}$ v7.0.

Each subject was presented with eight trials per testing day over 24 days. Subjects were presented with each stimulus sequence pair over the first 12 days and then each stimulus pair again over another 12 days, for a total of 192 trials per individual over two replicates. Trials included three variations in wind condition: calm, typical, and windy (Woo et al., 2009; Woo \& Rieucau, 2013).

\section{Statistical Analysis}

The video recorded trials were viewed in a digital format using Apple Quicktime ${ }^{\mathrm{TM}} \mathrm{v} 7.0$ to score behavioral responses. Each individual sequence was clipped to a 40 -s sequence ( $20 \mathrm{~s}$ on either side of the stimulus display event, which was marked). It was within the latter 20-s period that was the window for subjects to respond, and provided a finite period for recording responses.

I measured the conspicuousness of a signal by recording the orientation of the lizard to a display monitor, and I also measured the latency to respond to the onset of a playback display. Single orientation was defined as the lizard only orienting its head or body to one monitor, despite two displays being presented. Latency was defined as the number of individual frames (based on PAL-DV) that was necessary for the individual to orient to a stimulus. Double orientation was defined as the subject orienting to one display first, and then orientation to the display on the opposite monitor. Side biases were also measured 
during the presentation of the same two signals, and initial left-or-right orientation was recorded as well as latency to respond for both single orientation and double orientation. Individuals that did not respond to any conditions, such as no head or body orientation, were not recorded. Behaviors other than head and body orientation, and latency to respond were also not included in analyses. Individuals that did not respond to any conditions were not included in latency analysis. Accordingly, all responses to CON were removed from the analysis, as subjects elicited no behavioral responses to the control in these trials. In trials where CON was paired against a display (TF, PUBR, SAW), the subject responded to the onset of the visual display and would not respond to the control during single and double orientation, and side bias trials. Therefore, the inclusion of any analysis with CON trials would skew the results in favor of significant responses to the onset of displays. Hence, it was more meaningful to compare displays against each other to reduce any statistical bias (Hayes \& Preacher, 2014). The absence of responses to control stimuli have been shown in previous studies with jacky lizards (Woo \& Rieucau, 2012), whereas related studies that eliminated analyses with control stimuli have shown more reliable statistical comparisons (Woo \& Rieucau, 2013, 2015). Furthermore, it is likely that individuals may not have responded within the 20-s testing window, which has been commonly documented in empirical behavioral studies that involve ectotherms (Cardoso \& dos Santos Mendonça, 2019; Llewellyn et al., 2011).

When the numbers of individuals tested in a study are relatively few, the use of the number of responses to represent total sample size and its corresponding subset sample sizes in comparative analyses has been shown as a reliable method for measuring statistical significance in other species (Götz \& Janik, 2011; Lindemann-Biolsi \& Reichmuth, 2014; Martin \& Melfi, 2016; Stirman et al., 2016; Vaicekauskaite et a., 2019) and in previous studies with jacky dragons (Woo \& Burke, 2008; Woo et al., 2009, 2017; Woo \& Rieucau, 2012, 2013, 2015). Initially, the probability of orientation and response latency to stimulus pairs for all six individuals during each experimental treatment (see statistical analyses descriptions for Phase 1 and Phase 2 respectively for specific treatment levels) were categorized as the overall population that was used for factor analyses and more robust reporting. In contrast, the total number of responses during pairwise comparisons account for the total sample size $(N)$ for analyses. In reporting descriptive analyses that separated responses to individual stimuli during display pair presentation, the subsample of responses $(n)$ to a specific signal was used for these comparisons.

All data were analyzed using IBM $^{\circledR}$ SPSS $^{\circledR}$ Statistics v20 for Mac OS X (Armonk, NY). In addition, I reported all significance levels $(p<.05)$ and corresponding effect sizes $\left(\mu^{2}\right.$ and $\left.95 \% \mathrm{CI}\right)$.

\section{Phase 1 - Signal Competition Across Constant Visual Noise}

I used a general linear model (GLM) univariate analysis of variance (ANOVA) to test for a significant difference in probability of orientation and response latency for single orientation pairs (TFPUBR, TF-SAW, and PUBR-SAW). For double orientation pairs, I used a GLM univariate ANOVA to examine the probability of orientation and response latency initially to one visual signal (TF, PUBR, or SAW) and then followed by probability of orientation and response latency to the second signal (TF, PUBR, or SAW). Individual ID was selected as a random effect for single and double orientation analyses for the probability of orientation and latency responses.

Side biases (TF-TF, PUBR-PUBR, SAW-SAW) were examined using a GLM univariate ANOVA for single (left or right) and double orientation (left then right or right then left) pairs, and I tested for a main effect of single side biases responses and double orientation responses. Individual ID was again selected as a random effect for both single and double side bias orientation and response latency analyses.

I used a Wilcoxon signed ranks test for all probability of orientation pairwise comparisons. Paired samples correlations and t-tests were used for all pairwise comparisons of latency to respond. Descriptive analyses for average orientation rate of response and latency to respond were reported. 


\section{Phase 2 - Signal Competition Across Variable Levels of Environmental Noise}

For single orientation, I used a GLM univariate ANOVA to test for the main effect of wind condition (three levels: calm, typical, and windy), display pairs (three levels: TF-PUBR, TF-SAW, and PUBR-SAW), as well as an interaction between these factors for probability of orientation and response latency. To examine responses across wind conditions, I used a GLM multivariate ANOVA for probability of orientation and latency to compare double orientation responses when lizards oriented to one display first, and then to the opposite monitor. As in Phase 1, individual ID was also selected as a random effect for single and double orientation analyses for the probability of orientation and latency responses.

To examine single orientation to same-paired displays, I used a GLM MANOVA for both initial orientation and latency of response to examine the main effects of wind condition (three levels: calm, typical, and windy), display type (three levels: TF, PUBR, and SAW), and directional orientation (two levels: left and right) with possible interactions between them. Here, individual ID was once again selected as a random effect for both single and double side bias analyses.

Similar to Phase 1, I also used a Wilcoxon signed ranks test for all probability of orientation pairwise comparisons and I also used paired samples correlations and t-tests were used for all pairwise comparisons of latency to respond. Correspondingly, descriptive analyses for average orientation rate of response and latency to respond.

Lastly, I used Tukey's post-hoc tests to examine all pairwise treatments for signal pairs and side biases, except in the case of double-orientation for side biases. Unfortunately, I recorded relatively low numbers of responses during side biases double orientation trials, which provided insufficient data to perform meaningful statistical analyses. Hence, no statistical analyses for main effects or interactions were applicable for Phase 2 double orientation and latency side biases data.

\section{Results}

\section{Phase 1 - Signal Competition Across Constant Visual Noise}

\section{Signal Pairs}

Analyses of the probability of single orientation showed that lizards found the TF the most conspicuous motor pattern compared to all other display patterns, $F(2,5)=66.68, p<.001, \mu^{2}=0.102$. Pairwise comparisons showed significant differences in the probability of orientation between TF-PUBR, TF-SAW, and PUBR-SAW pairs (Table 2). TFs were more conspicuous than PUBRs in TF-PUBR pairs. Additionally, TFs were more conspicuous than SAWs when presented in TF-SAW pairs. PUBRs were more conspicuous than SAWs in during PUBR-SAW pair presentations (Figure 2a; Table 3).

Consistent with the probability of response data, latency to orient to only one display revealed a faster response to the TFs in comparison to other signals, $F(5,12)=28.13, p=.002, \mu^{2}=0.839$. Pairwise comparisons showed significant differences in the lizards' response latency to individual signals during the presentation of TF-PUBR, TF-SAW, and PUBR-SAW stimuli pairs (Table 2). Response latency to TFs in TF-PUBR pairs was shorter than responses to PUBRs. Individuals also responded faster to TFs as opposed to SAWs in TF-SAW pairings. Additionally, lizards responded to PUBRs more quickly than SAWs in PUBR-SAW pairings (Figure 2b; Table 3).

Probability of double orientation showed that lizards also found TF displays more conspicuous than other signals, $F(2,4)=188.39, p=.001, \mu^{2}=0.284$. Pairwise comparisons showed significant differences in the orientation probability for responding to one signal before another during competitive pairings between TF-PUBR, TF-SAW, and PUBR-SAW stimuli (Table 2). In TF-PUBR pairings, lizards would first orient to TFs before PUBRs. Consequently, in TF-SAW pairings, TFs were more conspicuous than SAWs. And consistent with motor pattern order, PUBRs were found to be more conspicuous than SAWs during PUBR-SAW pairings (Figure 3a; Table 3). 
Table 2

Phase 1: All Pairwise Comparisons for Probability of Orientation and Response Latency

\begin{tabular}{|c|c|c|c|c|c|c|c|c|c|c|c|c|c|c|c|c|c|}
\hline \multirow{3}{*}{ Comparison } & \multirow{3}{*}{ Display Pair } & \multicolumn{8}{|c|}{ Orientation } & \multicolumn{8}{|c|}{ Latency } \\
\hline & & \multicolumn{4}{|c|}{ Initial } & \multicolumn{4}{|c|}{ Double } & \multicolumn{4}{|c|}{ Initial } & \multicolumn{4}{|c|}{ Double } \\
\hline & & $N$ & $Z$ & $d f$ & $p$ & $N$ & $Z$ & $d f$ & $p$ & $N$ & $t$ & $d f$ & $p$ & $N$ & $T$ & $d f$ & $p$ \\
\hline \multirow{3}{*}{ Signal Pairs } & TF-PUBR & 27 & -3.87 & 26 & $<.001$ & 21 & -3.61 & 20 & $<.001$ & 27 & -2.20 & 25 & .042 & 21 & -3.82 & 20 & $<.001$ \\
\hline & TF-SAW & 30 & -5.10 & 29 & $<.001$ & 19 & -4.12 & 18 & $<.001$ & 30 & -2.14 & 28 & .027 & 19 & -9.16 & 18 & $<.001$ \\
\hline & PUBR-SAW & 31 & -4.12 & 30 & $<.001$ & 17 & -3.61 & 16 & $<.001$ & 31 & 1.71 & 29 & .045 & 17 & -6.56 & 16 & $<.001$ \\
\hline \multirow{3}{*}{ Side Bias } & $\mathrm{TF}$ & 17 & -1.73 & 16 & .083 & 9 & -1.00 & 8 & .32 & 17 & -2.95 & 15 & .02 & 9 & 0.10 & 8 & .93 \\
\hline & PUBR & 22 & -1.41 & 21 & .16 & 2 & 0.00 & 1 & 1.00 & 22 & 0.61 & 20 & .55 & 2 & 0.17 & 1 & .88 \\
\hline & SAW & 17 & -1.73 & 16 & .083 & 6 & 0.00 & 5 & 1.00 & 17 & -0.61 & 15 & .55 & 6 & 0.26 & 5 & .80 \\
\hline
\end{tabular}

Note. Pairwise comparisons include single and double orientation for signal pairs and side biases. 
Woo 425

Figure 2

Response to Display Pairs ( $M \pm S E M)$ Across Signal Pairs for Single Orientation During Phase 1: a) Proportion and b) Latency

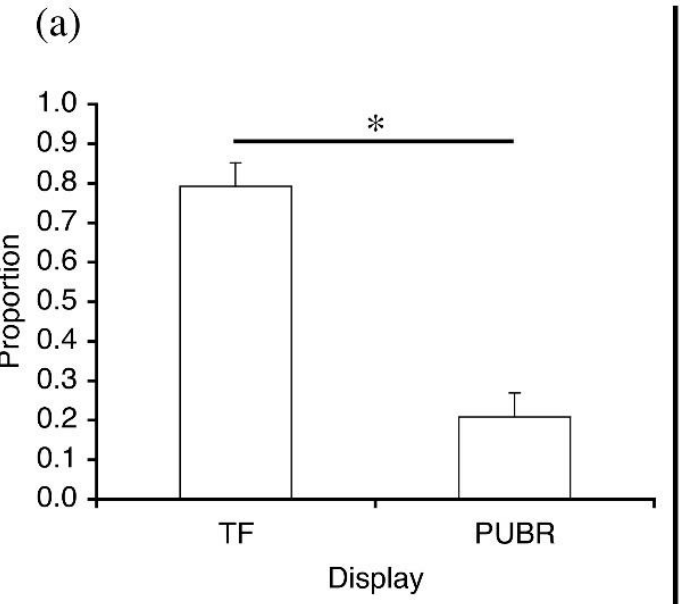

(b)
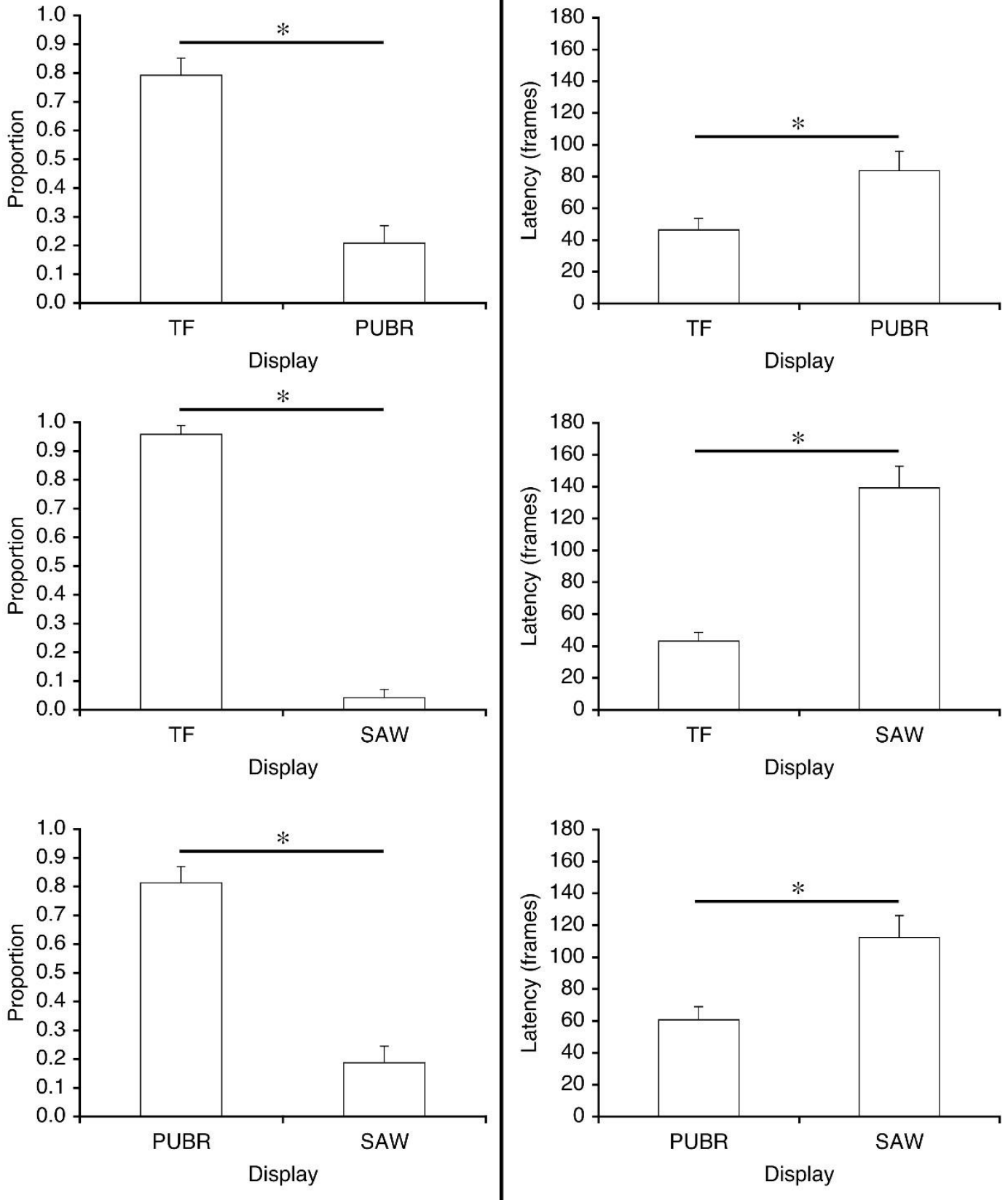

Note. $*$ indicates a significant difference between display pairs $(p<.05)$. 
Table 3

Phase 1: Descriptive Statistical Comparisons for Probability of Orientation and Response Latency to Individual Signals when Competing Display Pairs were Shown to Lizards and the Video Background was Similar in All Stimuli

\begin{tabular}{|c|c|c|c|c|c|c|c|c|c|c|c|c|c|c|c|c|c|}
\hline \multirow{3}{*}{ Pairs } & \multirow{3}{*}{ Signal } & \multicolumn{8}{|c|}{ Orientation } & \multicolumn{8}{|c|}{ Latency } \\
\hline & & \multicolumn{4}{|c|}{ Initial } & \multicolumn{4}{|c|}{ Double } & \multicolumn{4}{|c|}{ Initial } & \multicolumn{4}{|c|}{ Double } \\
\hline & & $n$ & $M$ & $S D$ & $95 \% \mathrm{CI}$ & $n$ & $M$ & $S D$ & $95 \% \mathrm{CI}$ & $n$ & $M$ & $S D$ & $95 \% \mathrm{CI}$ & $n$ & $M$ & $S D$ & $95 \% \mathrm{CI}$ \\
\hline \multirow{2}{*}{ TF-PUBR } & $\mathrm{TF}$ & 21 & 0.81 & 0.40 & $\begin{array}{l}0.06, \\
0.96]\end{array}$ & 17 & 0.81 & 0.40 & $\begin{array}{l}{[0.64,} \\
0.98]\end{array}$ & 21 & 48.18 & 36.68 & $\begin{array}{l}32.46 \\
63.43]\end{array}$ & 17 & 41.69 & 50.13 & $\begin{array}{c}22.43 \\
60.96]\end{array}$ \\
\hline & PUBR & 6 & 0.23 & 0.43 & $\begin{array}{l}{[0.07,} \\
0.39]\end{array}$ & 4 & 0.19 & 0.25 & $\begin{array}{l}{[0.02,} \\
0.36]\end{array}$ & 6 & 50.50 & 59.59 & $\begin{array}{l}{[2.82} \\
98.18]\end{array}$ & 4 & 102.08 & 62.23 & $\begin{array}{l}\text { [37.77, } \\
126.38]\end{array}$ \\
\hline \multirow{2}{*}{ TF-SAW } & $\mathrm{TF}$ & 28 & 0.93 & 0.26 & $\begin{array}{l}{[0.84,} \\
1.02]\end{array}$ & 17 & 0.95 & 0.23 & $\begin{array}{l}0.84, \\
1.05]\end{array}$ & 28 & 48.42 & 38.58 & $\begin{array}{l}{[34.37,} \\
62.46]\end{array}$ & 17 & 35.85 & 35.11 & $\begin{array}{l}22.35 \\
49.34]\end{array}$ \\
\hline & SAW & 2 & 0.67 & 0.25 & $\begin{array}{c}{[-0.02} \\
0.16]\end{array}$ & 2 & 0.53 & 0.23 & $\begin{array}{c}{[-0.05} \\
0.16]\end{array}$ & 2 & 62.50 & 61.52 & $\begin{array}{l}{[-22.76} \\
147.76]\end{array}$ & 2 & 152.08 & 54.33 & $\begin{array}{c}{[131.20} \\
172.96]\end{array}$ \\
\hline \multirow{2}{*}{ PUBR-SAW } & PUBR & 24 & 0.77 & 0.43 & $\begin{array}{c}0.63 \\
0.38]\end{array}$ & 15 & 0.88 & 0.43 & $\begin{array}{c}0.73, \\
1.04]\end{array}$ & 24 & 61.13 & 51.38 & $\begin{array}{l}41.57 \\
82.68]\end{array}$ & 15 & 37.67 & 40.22 & $\begin{array}{c}20.41 \\
54.87]\end{array}$ \\
\hline & SAW & 7 & 0.23 & 0.43 & $\begin{array}{l}{[0.08,} \\
0.38]\end{array}$ & 2 & 0.12 & 0.33 & $\begin{array}{c}{[-0.04} \\
0.28]\end{array}$ & 7 & 76.71 & 58.63 & $\begin{array}{l}{[21.50} \\
102.75]\end{array}$ & 2 & 140.43 & 54.53 & $\begin{array}{r}{[114.97} \\
165.89]\end{array}$ \\
\hline
\end{tabular}


Figure 3

Response to Display Pairs ( $M \pm$ SEM) Across Signal Pairs During Double Orientation Encounters for Phase 1: a) Proportion and b) Latency

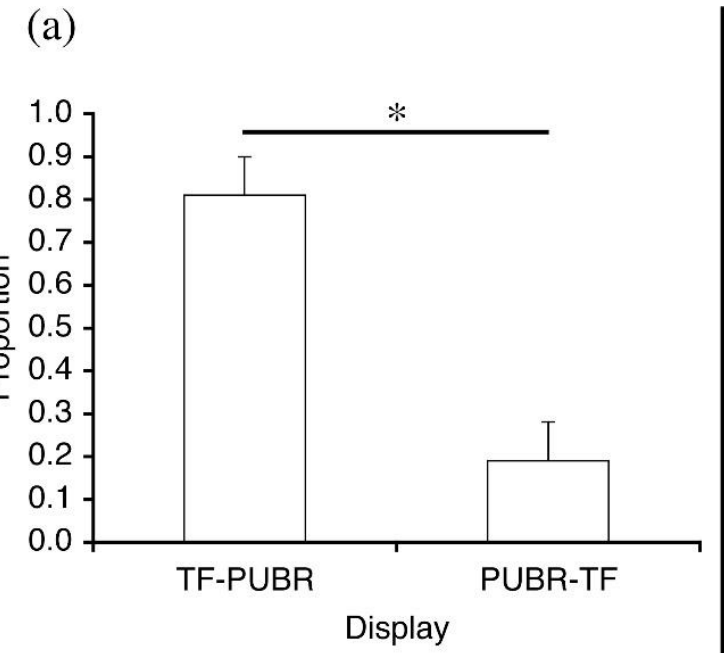

(b)
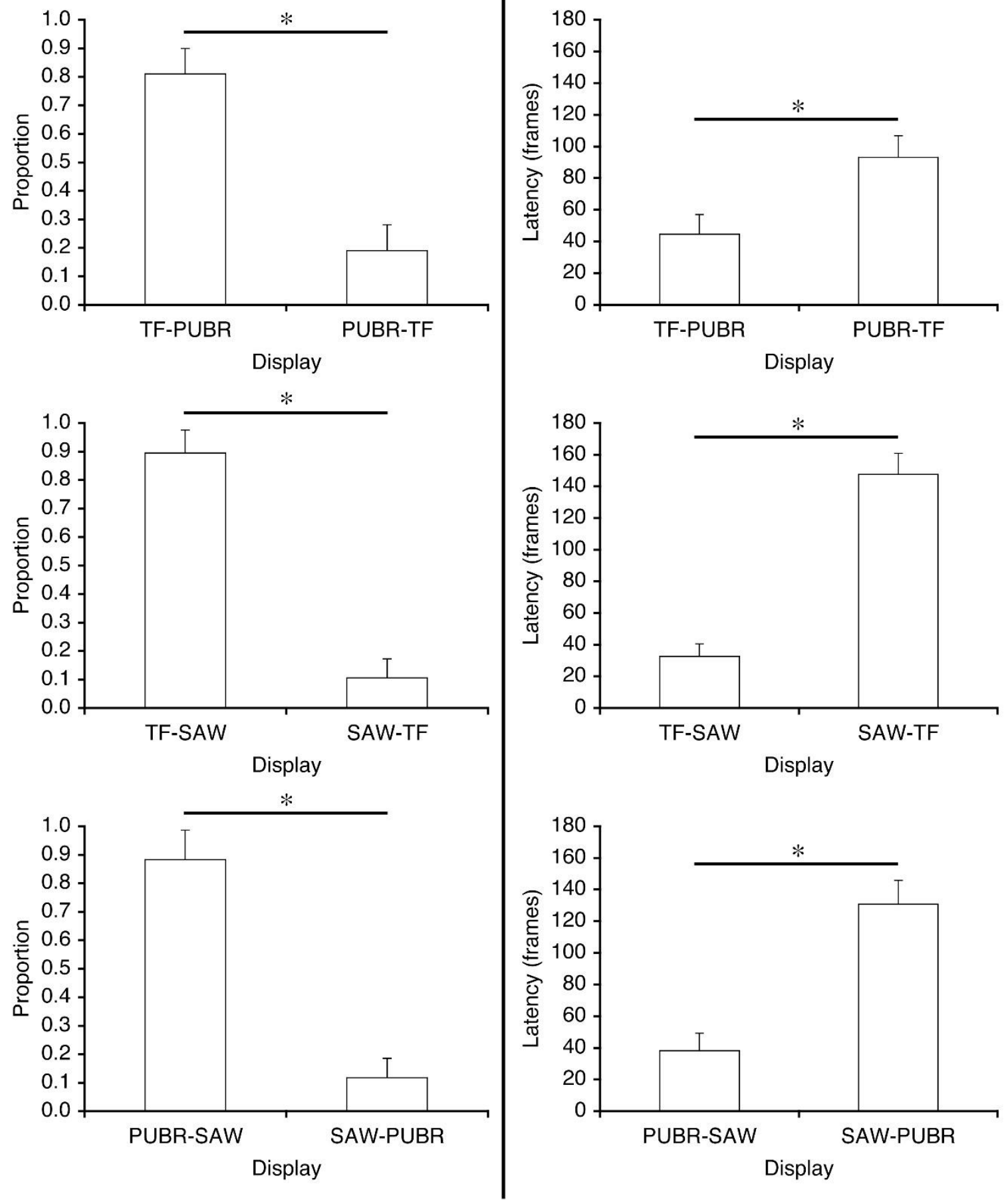

Note. $*$ indicates a significant difference between display pairs $(p<.05)$. 
Double orientation showed a significant latency to respond to one signal over another, $F(5,25)=$ $12.35, p<.001, \mu^{2}=0.652$. Lizards once again showed a significant difference in latency to respond during TF-PUBR, TF-SAW, and PUBR-SAW stimuli pairs (Table 2). Lizards responded faster to TFs than PUBRs in TF-PUBR pairs, TFs than SAWs in TF-SAW pairs, and PUBRs over SAWs in PUBR-SAW pairs when they oriented sequentially to opposing monitors (Figure 3b; Table 3).

\section{Side Biases}

Analysis of single orientation responses revealed no significant pairwise comparisons (Table 4), except for the initial response latency for the TF pairing was significant. In addition, the probability of orientation (Figure 4a) and response latency (Figure 4b) during same pair trials showed no significant main effect for type of display or direction and no interaction between these two factors (Table 4).

Similarly, double orientation also revealed no significant pairwise comparisons (Table 4). Double orientation to competing displays of the same type for probability of orientation (Figure 5a) and latency to respond (Figure 5b) showed no main effect for type of display or direction, and no interaction between these two factors (Table 4).

\section{Phase 2 - Signal Competition Across Variable Levels of Environmental Noise}

\section{Signal Pairs}

Probability of single orientation showed a main effect of motor pattern type, $F(2,5)=66.41, p<$ $.001, \mu^{2}=0.337$, but no main effect for wind condition, $F(2,5)=2.846, p=.105, \mu^{2}=0.023$, and no interaction between these two factors, $F(2,4)=0.436, p=.781, \mu^{2}=0.079$. Pairwise comparisons showed significant differences in the probability of orientation response in TF-PUBR, TF-SAW, and PUBR-SAW pairings across all wind conditions (Table 5). TFs were found to be the most conspicuous motor pattern display in comparison to PUBRs during TF-PUBR pairings and when compared to SAWs during TF-SAW pairings across calm, typical, and windy conditions. Orientation probability for PUBR-SAW pairings also showed that PUBRs were more conspicuous than SAWs across calm, typical, and windy treatments (Figure 6a; Table 6). Further post-hoc analysis also showed that the TF was the most conspicuous in all wind conditions when paired against a PUBR or SAW $(p<.05)$. PUBRs were also more conspicuous that SAW displays $(p<.05)$. Response orientation probability was fairly stable, as there was no difference for conspicuousness for all pairwise comparisons between calm and typical conditions $(p>.05)$. However, probability for orienting was consistently lower during windier conditions $(p<.05)$.

Response latency data showed no main effect of display, $F(2,5)=1.492, p=.192, \mu^{2}=0.011$, wind condition, $F(2,5)=0.496, p=.610, \mu^{2}=0.004$, or an interaction between them, $F(2,4)=1.001, p=.407$, $\mu^{2}=0.014$. Unlike the probability of orientation results, pairwise comparisons for response latency showed only one significant comparison for the TF-SAW pair during the calm wind condition (Table 5). Individuals responded faster to TFs in comparison to SAWs during calm conditions (Figure 6b; Table 6). Additional post-hoc tests revealed a significantly faster response latency to TFs than SAWs in typical conditions ( $p$ $<.05)$, and to PUBRs than SAWs in windy conditions $(p<.05)$. No other comparisons were significant $(p$ $>.05)$. 
Table 4

Phase 1: Main Effects and Interactions for Side Bias Responses for Single and Double Orientation for Probability of Orientation and Latency to Response

\begin{tabular}{|c|c|c|c|c|c|c|c|c|c|c|c|c|c|c|c|c|}
\hline \multirow{3}{*}{ Measure } & \multicolumn{8}{|c|}{ Initial } & \multicolumn{8}{|c|}{ Double } \\
\hline & \multicolumn{4}{|c|}{ Orientation } & \multicolumn{4}{|c|}{ Latency } & \multicolumn{4}{|c|}{ Orientation } & \multicolumn{4}{|c|}{ Latency } \\
\hline & $F$ & $d f$ & $p$ & $\mu^{2}$ & $F$ & $d f$ & $p$ & $\mu^{2}$ & $F$ & $d f$ & $p$ & $\mu^{2}$ & $F$ & $d f$ & $p$ & $\mu^{2}$ \\
\hline Display & 0.59 & 2,5 & .57 & 0.10 & 1.33 & 2,5 & .31 & 0.21 & 1.53 & 2,3 & .06 & 0.68 & 0.16 & 2,5 & 0.86 & .02 \\
\hline Direction & 0.89 & 1,5 & .52 & 0.30 & 0.01 & 1,5 & .31 & 0.21 & 1.88 & 1,3 & .08 & 0.94 & 1.38 & 1,5 & 0.28 & .12 \\
\hline Display*Direction & 1.06 & 5,10 & .41 & 0.23 & 0.38 & 2,10 & .70 & 0.54 & 0.18 & 3,8 & .91 & 0.06 & 1.26 & 1,2 & 0.39 & .22 \\
\hline
\end{tabular}


Figure 4

Initial Orientation Side Bias for Same-Pairs (M \pm SEM) Presentations for Phase 1 Showing No Significant Side Bias: a) Proportion and b) Latency

(a)

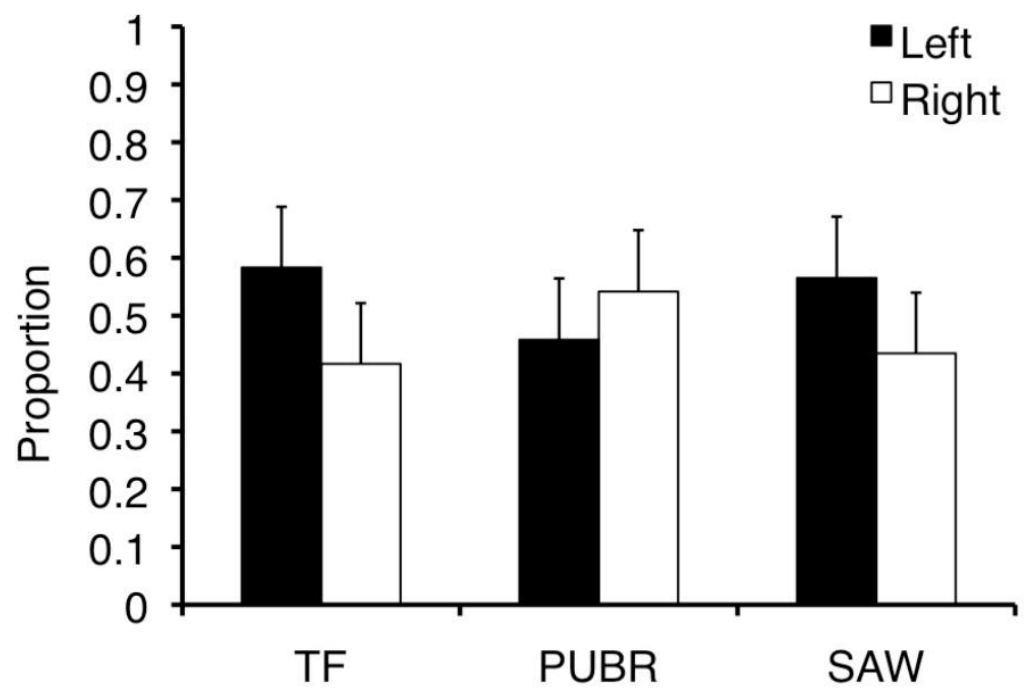

Side Bias Display Pairs

(b)

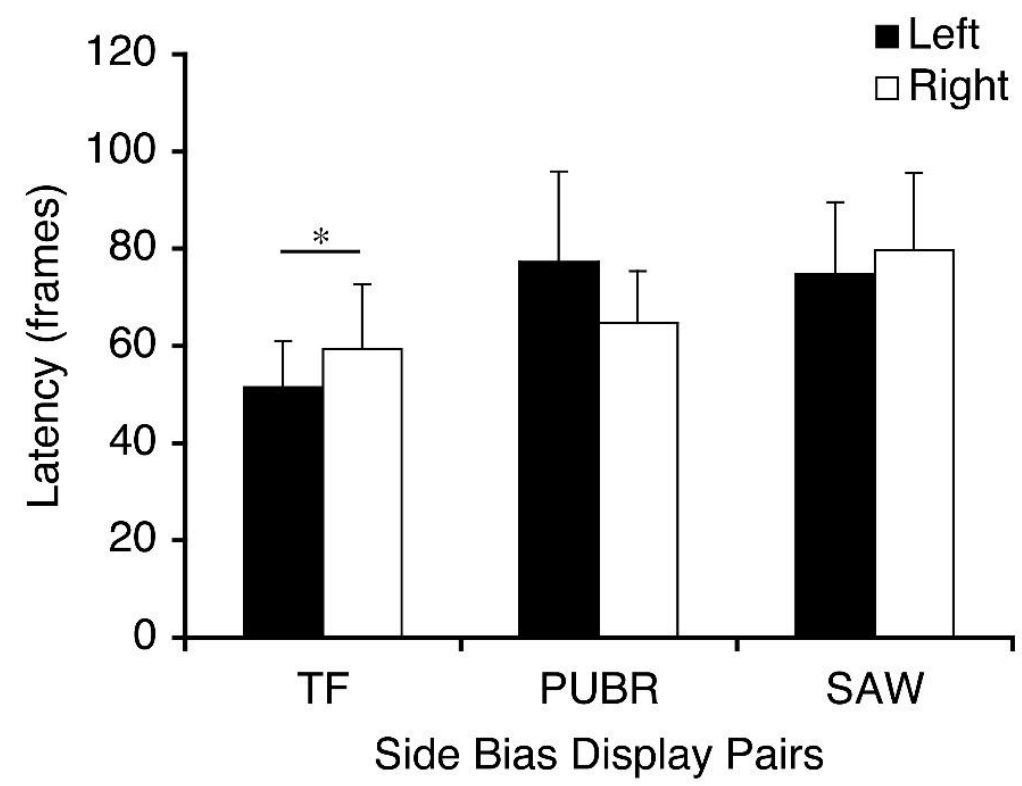

Note. * indicates a significant difference between display pairs $(p<.05)$. 
Figure 5

Double Orientation Side Bias for Same-Pairs $(M \pm S E M)$ Presentations for Phase 1 Also Showing No Significant Side Bias: a) Proportion and b) Latency

(a)

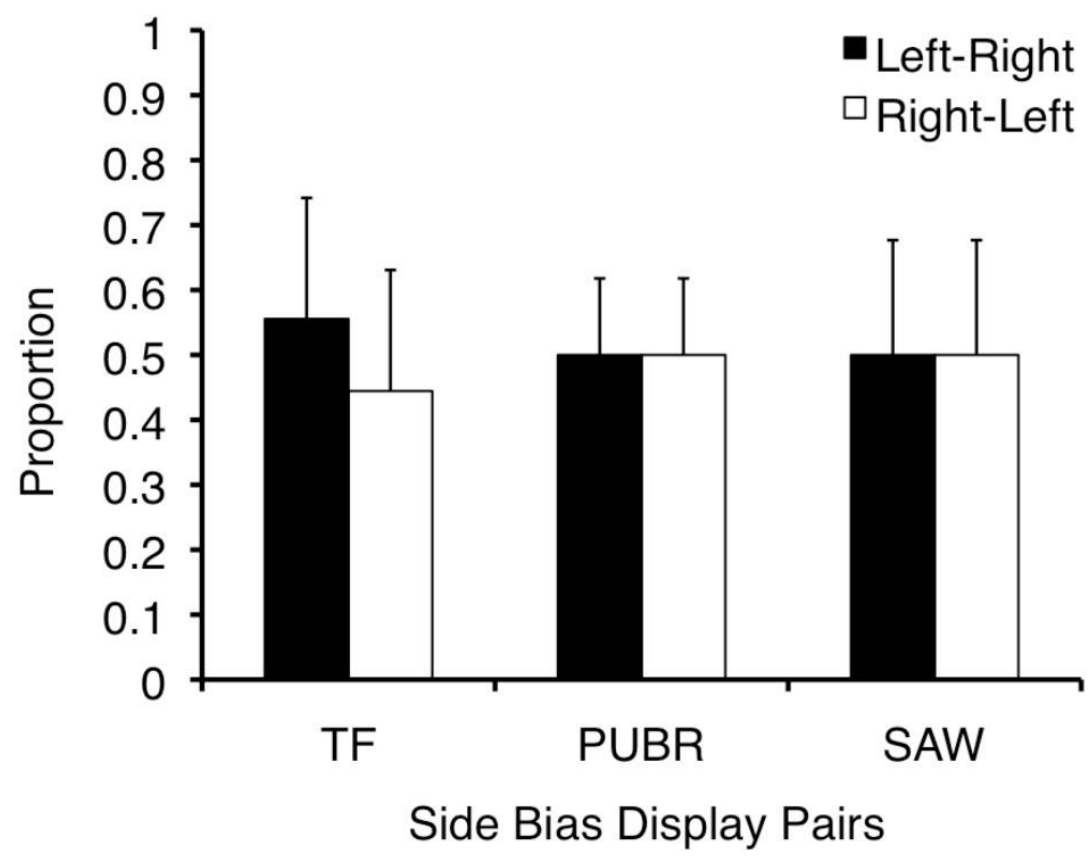

(b)

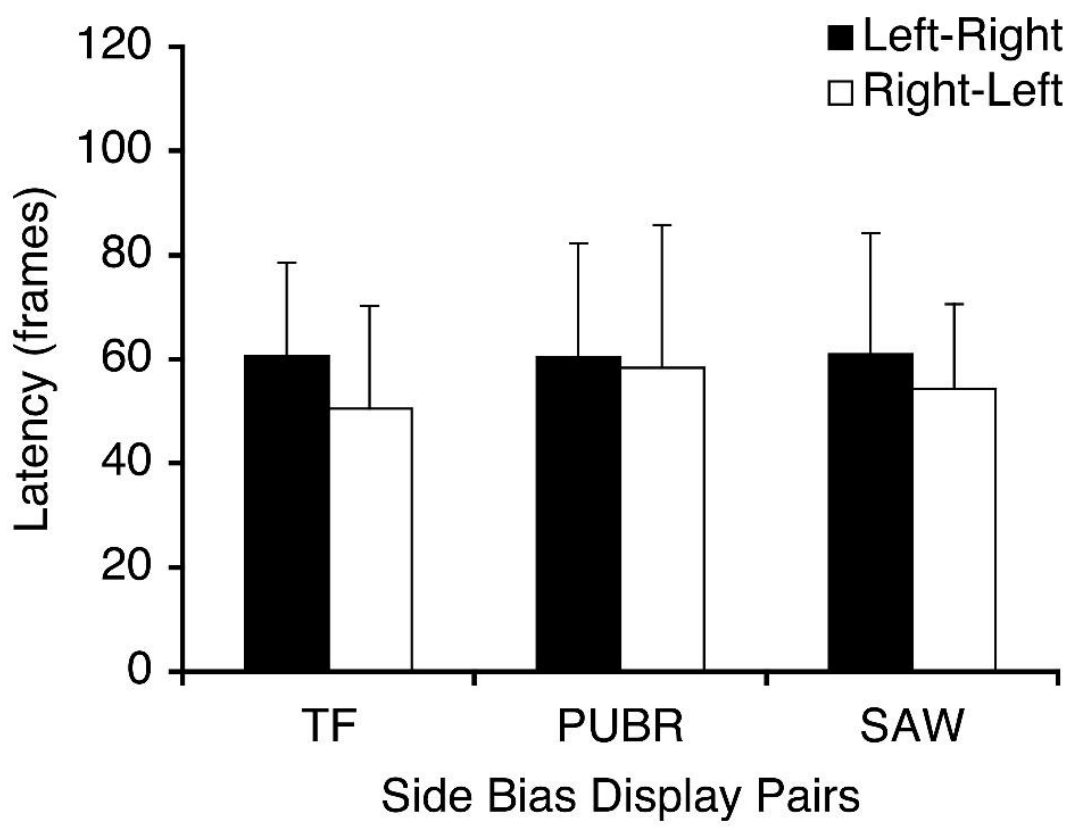

Note. * indicates a significant difference between display pairs $(p<.05)$. 
Table 5

Phase 2: All Pairwise Comparisons for Probability of Orientation and Response Latency

\begin{tabular}{|c|c|c|c|c|c|c|c|c|c|c|c|c|c|c|c|c|c|c|}
\hline \multirow{3}{*}{ Wind } & \multirow{3}{*}{ Comparison } & \multirow{3}{*}{ Display Pair } & \multicolumn{8}{|c|}{ Orientation } & \multicolumn{8}{|c|}{ Latency } \\
\hline & & & \multicolumn{4}{|c|}{ Initial } & \multicolumn{4}{|c|}{ Double } & \multicolumn{4}{|c|}{ Initial } & \multicolumn{4}{|c|}{ Double } \\
\hline & & & $N$ & $Z$ & $d f$ & $p$ & $N$ & $Z$ & $d f$ & $p$ & $N$ & $t$ & $d f$ & $p$ & $N$ & $t$ & $d f$ & $p$ \\
\hline \multirow{6}{*}{ Calm } & \multirow{3}{*}{ Signal Pairs } & TF-PUBR & 48 & -4.69 & 47 & $<.001$ & 4 & -2.00 & 3 & .046 & 48 & -0.38 & 46 & .706 & 2 & -1.63 & 1 & .351 \\
\hline & & TF-SAW & 41 & -5.20 & 40 & $<.001$ & 12 & -2.45 & 11 & .014 & 41 & -2.13 & 39 & .040 & 6 & 0.20 & 5 & .848 \\
\hline & & PUBR-SAW & 44 & -4.58 & 43 & $<.001$ & 10 & -2.24 & 9 & .025 & 44 & 0.28 & 42 & .779 & 5 & 0.10 & 4 & .927 \\
\hline & \multirow{3}{*}{ Side Bias } & $\mathrm{TF}$ & 26 & 0.00 & 25 & 1.000 & 4 & 0.00 & 3 & 1.000 & 26 & 0.36 & 24 & .721 & 2 & -0.26 & 1 & .820 \\
\hline & & PUBR & 27 & -2.50 & 26 & .14 & $*$ & $*$ & $*$ & $*$ & 27 & -0.25 & 25 & .805 & 2 & 1.06 & 1 & .399 \\
\hline & & SAW & 26 & 0.00 & 25 & 1.000 & 4 & 0.00 & 3 & 1.000 & 26 & -0.06 & 24 & .954 & 6 & -0.40 & 5 & .699 \\
\hline \multirow{6}{*}{ Typical } & \multirow{3}{*}{ Signal Pairs } & TF-PUBR & 44 & -4.58 & 43 & $<.001$ & 10 & -1.00 & 9 & .317 & 44 & -0.74 & 42 & .461 & 5 & -0.60 & 4 & .581 \\
\hline & & TF-SAW & 40 & -5.10 & 39 & $<.001$ & 12 & -1.41 & 11 & .157 & 40 & -1.83 & 38 & .077 & 6 & -1.18 & 5 & .293 \\
\hline & & PUBR-SAW & 40 & -5.75 & 39 & $<.001$ & 8 & -2.00 & 7 & .046 & 40 & -0.15 & 38 & .884 & 4 & -1.98 & 3 & .142 \\
\hline & \multirow{3}{*}{ Side Bias } & TF & 23 & -1.00 & 22 & .317 & $*$ & $*$ & $*$ & $*$ & 23 & -0.58 & 21 & .568 & $*$ & $*$ & $*$ & $*$ \\
\hline & & PUBR & 24 & -1.41 & 23 & .157 & 6 & -1.00 & 5 & .317 & 24 & 0.70 & 22 & .510 & 4 & 0.26 & 3 & .643 \\
\hline & & SAW & 28 & -2.00 & 27 & .046 & 6 & -2.00 & 5 & .046 & 28 & -0.60 & 26 & .553 & 8 & -1.27 & 7 & .226 \\
\hline \multirow{6}{*}{ Windy } & \multirow{3}{*}{ Signal Pairs } & TF-PUBR & 28 & -3.46 & 27 & .001 & 14 & -2.24 & 13 & .025 & 28 & 0.07 & 26 & .945 & 6 & -0.80 & 5 & .458 \\
\hline & & TF-SAW & 26 & -3.46 & 25 & .001 & 12 & -1.41 & 11 & .157 & 26 & 0.08 & 24 & .939 & 6 & -0.18 & 5 & .862 \\
\hline & & PUBR-SAW & 25 & -3.46 & 24 & .001 & 10 & -2.24 & 9 & .025 & 25 & -1.99 & 23 & .059 & 5 & -5.67 & 4 & .005 \\
\hline & \multirow{3}{*}{ Side Bias } & TF & 20 & -2.24 & 19 & .046 & 4 & -1.41 & 3 & .157 & 20 & -1.24 & 18 & .232 & 4 & -0.08 & 3 & .936 \\
\hline & & PUBR & 15 & -1.41 & 14 & .157 & $*$ & $*$ & $*$ & $*$ & 15 & 1.14 & 13 & .274 & $*$ & $*$ & $*$ & $*$ \\
\hline & & SAW & 17 & -2.24 & 16 & .025 & 4 & -2.00 & 3 & .046 & 17 & -1.23 & 15 & .236 & 2 & -2.88 & 1 & .103 \\
\hline
\end{tabular}

Note. Pairwise comparisons include single and double orientation for signal pairs and side biases. $(*)$ indicate the absence of enough data points to perform statistical analysis. 
Figure 6

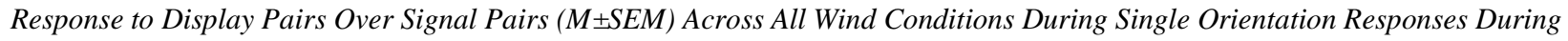
Phase 2: a) Proportion and b) Latency
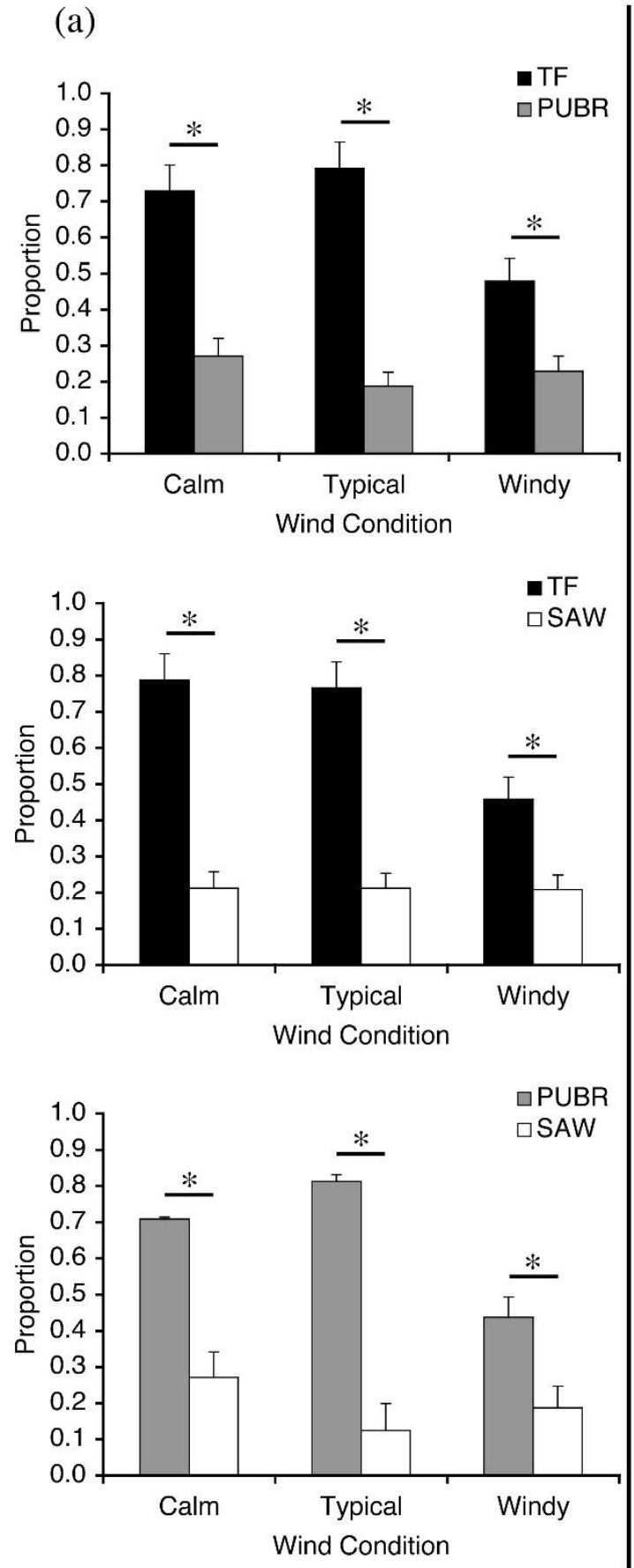

(b)
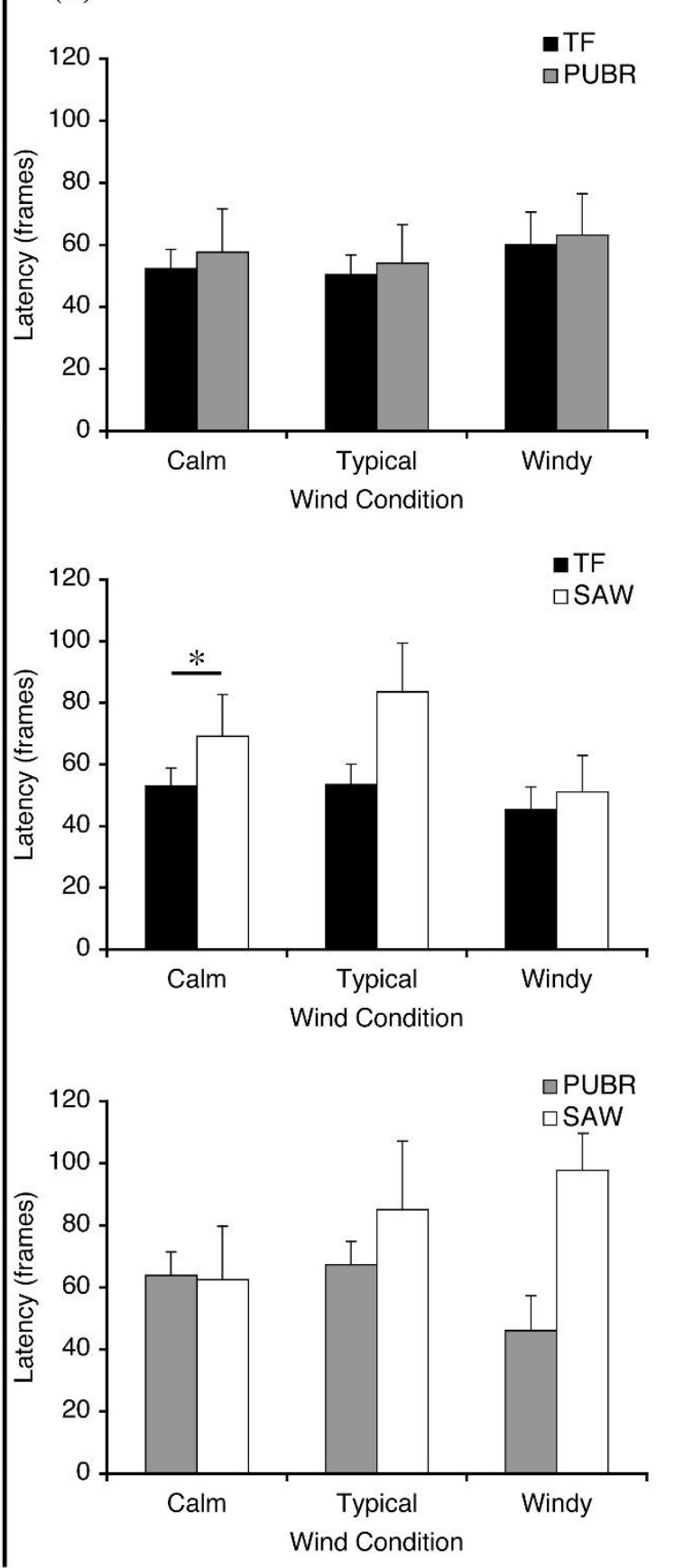

Note. $*$ indicates a significant difference between display pairs $(p<0.05)$. 


\section{Table 6}

Phase 2. Descriptive Statistical Comparisons for Probability of Orientation and Response Latency to Individual Signals When Competing Display Pairs Were Shown at Assigned Wind Conditions

\begin{tabular}{|c|c|c|c|c|c|c|c|c|c|c|c|c|c|c|c|c|c|c|}
\hline \multirow{3}{*}{ Wind } & \multirow{3}{*}{ Pair } & \multirow{3}{*}{ Signal } & \multicolumn{8}{|c|}{ Orientation } & \multicolumn{8}{|c|}{ Duration } \\
\hline & & & \multicolumn{4}{|c|}{ Initial } & \multicolumn{4}{|c|}{ Double } & \multicolumn{4}{|c|}{ Initial } & \multicolumn{4}{|c|}{ Double } \\
\hline & & & $n$ & $M$ & $S D$ & $95 \%$ CI & $n$ & $M$ & $S D$ & $95 \% \mathrm{CI}$ & $n$ & $M$ & $S D$ & $95 \% \mathrm{CI}$ & $n$ & $M$ & $S D$ & $95 \% \mathrm{CI}$ \\
\hline \multirow{6}{*}{ Calm } & \multirow{2}{*}{$\begin{array}{c}\text { TF- } \\
\text { PUBR }\end{array}$} & $\mathrm{TF}$ & 35 & 0.73 & 0.45 & $\begin{array}{c}{[0.58} \\
0.89]\end{array}$ & 4 & 0.75 & 0.50 & $\begin{array}{c}0.18 \\
1.32]\end{array}$ & 35 & 52.94 & 37.51 & $\begin{array}{c}\text { [40.48, } \\
65.40]\end{array}$ & 4 & 40.01 & 14.14 & $\begin{array}{c}{[20.44,} \\
59.60]\end{array}$ \\
\hline & & PUBR & 13 & 0.27 & 0.45 & $\begin{array}{c}{[0.03,} \\
0.52]\end{array}$ & 4 & 0.25 & 0.50 & $\begin{array}{c}{[-0.73,} \\
1.23] \\
\end{array}$ & 15 & 58.17 & 50.36 & $\begin{array}{l}{[29.39} \\
86.64] \\
\end{array}$ & 4 & 53.31 & 2.83 & $\begin{array}{r}{[49.08,} \\
56.92]\end{array}$ \\
\hline & \multirow{2}{*}{$\begin{array}{l}\text { TF- } \\
\text { SAW }\end{array}$} & $\mathrm{TF}$ & 31 & 0.79 & 0.41 & $\begin{array}{c}{[0.66,} \\
0.92]\end{array}$ & 6 & 0.88 & 0.41 & $\begin{array}{l}{[0.48,} \\
1.19]\end{array}$ & 31 & 53.61 & 35.01 & $\begin{array}{c}{[40.72} \\
65.41]\end{array}$ & 6 & 52.67 & 36.49 & $\begin{array}{l}23.47, \\
81.86]\end{array}$ \\
\hline & & SAW & 10 & 0.21 & 0.42 & $\begin{array}{c}{[-0.04} \\
0.47]\end{array}$ & 6 & 0.17 & 0.41 & $\begin{array}{l}{[-.63} \\
0.97]\end{array}$ & 10 & 83.10 & 49.21 & $\begin{array}{l}\text { [52.60, } \\
113.60]\end{array}$ & 6 & 45.83 & 54.12 & $\begin{array}{l}{[2.53,} \\
89.14]\end{array}$ \\
\hline & \multirow{2}{*}{$\begin{array}{l}\text { PUBR } \\
\text {-SAW }\end{array}$} & PUBR & 34 & 0.72 & 0.45 & $\begin{array}{c}0.57 \\
0.88]\end{array}$ & 5 & 0.60 & 0.55 & $\begin{array}{c}{[-0.02} \\
1.22]\end{array}$ & 34 & 61.46 & 41.13 & $\begin{array}{l}47.42 \\
75.49]\end{array}$ & 5 & 84.00 & 77.37 & $\begin{array}{c}{[7.81,} \\
160.19]\end{array}$ \\
\hline & & SAW & 13 & 0.28 & 0.34 & $\begin{array}{c}{[0.03,} \\
0.52]\end{array}$ & 5 & 0.40 & 0.55 & $\begin{array}{c}{[-0.36} \\
1.16] \\
\end{array}$ & 13 & 57.09 & 53.55 & $\begin{array}{r}{[25.45} \\
88.74] \\
\end{array}$ & 5 & 77.25 & 96.96 & $\begin{array}{l}{[-17.76,} \\
172.26]\end{array}$ \\
\hline \multirow{6}{*}{$\begin{array}{c}\text { Typica } \\
1\end{array}$} & \multirow{2}{*}{$\begin{array}{c}\text { TF- } \\
\text { PUBR }\end{array}$} & $\mathrm{TF}$ & 37 & 0.81 & 0.40 & $\begin{array}{c}0.68, \\
0.94]\end{array}$ & 5 & 0.60 & 0.55 & $\begin{array}{c}-0.02 \\
1.22]\end{array}$ & 37 & 53.08 & 41.10 & $\begin{array}{c}{[39.84} \\
66.33]\end{array}$ & 5 & 30.20 & 36.10 & $\begin{array}{l}{[-1.44,} \\
61.84]\end{array}$ \\
\hline & & PUBR & 7 & 0.19 & 0.45 & $\begin{array}{c}{[-0.07,} \\
0.45]\end{array}$ & 5 & 0.40 & 0.55 & $\begin{array}{c}{[-0.36} \\
1.16]\end{array}$ & 7 & 65.86 & 44.76 & $\begin{array}{c}{[32.70} \\
99.02]\end{array}$ & 5 & 37.60 & 33.07 & $\begin{array}{l}{[8.61,} \\
66.59]\end{array}$ \\
\hline & \multirow{2}{*}{$\begin{array}{l}\text { TF- } \\
\text { SAW }\end{array}$} & $\mathrm{TF}$ & 32 & 0.78 & 0.45 & $\begin{array}{l}{[0.65,} \\
0.92]\end{array}$ & 6 & 0.67 & 0.52 & $\begin{array}{l}{[0.16,} \\
1.17]\end{array}$ & 32 & 55.97 & 33.96 & $\begin{array}{c}{[44.20} \\
67.74]\end{array}$ & 6 & 40.50 & 67.36 & $\begin{array}{r}{[-13.40,} \\
94.40]\end{array}$ \\
\hline & & SAW & 8 & 0.27 & 0.41 & $\begin{array}{c}{[0.04,} \\
0.47]\end{array}$ & 6 & 0.33 & 0.52 & $\begin{array}{c}{[-0.38,} \\
1.05]\end{array}$ & 8 & 85.25 & 65.43 & $\begin{array}{l}\text { [41.99, } \\
128.51]\end{array}$ & 6 & 81.17 & 54.81 & $\begin{array}{l}\text { [37.31, } \\
125.02]\end{array}$ \\
\hline & \multirow{2}{*}{$\begin{array}{l}\text { PUBR } \\
\text {-SAW }\end{array}$} & PUBR & 39 & 0.87 & 0.45 & $\begin{array}{c}0.76 \\
0.98]\end{array}$ & 4 & 0.75 & 0.50 & $\begin{array}{l}0.18, \\
1.32]\end{array}$ & 39 & 71.85 & 43.41 & $\begin{array}{l}57.27 \\
86.44]\end{array}$ & 4 & 28.50 & 48.34 & $\begin{array}{c}{[-18.88,} \\
75.88]\end{array}$ \\
\hline & & SAW & 6 & 0.13 & 0.34 & $\begin{array}{c}{[-0.14} \\
0.41] \\
\end{array}$ & 4 & 0.25 & 0.50 & $\begin{array}{c}{[-0.73,} \\
1.23] \\
\end{array}$ & 6 & 74.83 & 58.75 & $\begin{array}{l}\text { [27.83, } \\
121.84]\end{array}$ & 4 & 100.25 & 83.56 & $\begin{array}{l}{[18.37,} \\
182.13]\end{array}$ \\
\hline \multirow{6}{*}{ Windy } & \multirow{2}{*}{$\begin{array}{l}\text { TF- } \\
\text { PUBR }\end{array}$} & $\mathrm{TF}$ & 17 & 0.68 & 0.48 & $\begin{array}{c}{[0.48,} \\
0.87]\end{array}$ & 7 & 0.86 & 0.38 & $\begin{array}{c}0.56, \\
1.16]\end{array}$ & 17 & 67.88 & 51.67 & $\begin{array}{l}{[43.32} \\
92.44]\end{array}$ & 7 & 38.17 & 34.89 & $\begin{array}{r}{[10.25,} \\
66.08]\end{array}$ \\
\hline & & PUBR & 11 & 0.32 & 0.48 & $\begin{array}{c}{[0.04,} \\
0.60]\end{array}$ & 7 & 0.14 & 0.38 & $\begin{array}{c}{[-0.60,} \\
0.88]\end{array}$ & 11 & 66.46 & 55.64 & $\begin{array}{l}\text { [33.58, } \\
99.33] \\
\end{array}$ & 7 & 57.17 & 52.73 & $\begin{array}{l}{[14.98,} \\
99.36]\end{array}$ \\
\hline & \multirow{2}{*}{$\begin{array}{l}\text { TF- } \\
\text { SAW }\end{array}$} & $\mathrm{TF}$ & 18 & 0.69 & 0.47 & $\begin{array}{l}0.49, \\
0.88]\end{array}$ & 6 & 0.67 & 0.52 & $\begin{array}{l}{[0.16,} \\
1.17]\end{array}$ & 18 & 48.33 & 29.77 & $\begin{array}{c}34.58, \\
62.09]\end{array}$ & 6 & 42.83 & 53.60 & $\begin{array}{l}-0.06, \\
85.72]\end{array}$ \\
\hline & & SAW & 8 & 0.31 & 0.47 & $\begin{array}{l}{[0.02,} \\
0.60]\end{array}$ & 6 & 0.33 & 0.52 & $\begin{array}{c}{[-0.38,} \\
1.05]\end{array}$ & 8 & 47.13 & 50.10 & $\begin{array}{l}{[12.41} \\
81.85]\end{array}$ & 6 & 48.17 & 37.27 & $\begin{array}{l}{[18.35,} \\
77.99]\end{array}$ \\
\hline & \multirow{2}{*}{$\begin{array}{l}\text { PUBR } \\
\text {-SAW }\end{array}$} & PUBR & 15 & 0.70 & 0.47 & $\begin{array}{l}0.50, \\
0.90]\end{array}$ & 5 & 0.60 & 0.55 & $\begin{array}{c}-0.02 \\
1.22]\end{array}$ & 15 & 51.27 & 50.68 & $\begin{array}{l}{[25.62,} \\
76.914\end{array}$ & 5 & 30.40 & 45.33 & $\begin{array}{l}{[-9.33} \\
70.13]\end{array}$ \\
\hline & & SAW & 10 & 0.30 & 0.41 & $\begin{array}{c}{[-0.01} \\
0.61]\end{array}$ & 5 & 0.40 & 0.55 & $\begin{array}{c}{[-0.36} \\
1.16]\end{array}$ & 10 & 93.10 & 52.78 & $\begin{array}{l}{[60.39} \\
125.81]\end{array}$ & 5 & 106.80 & 40.92 & $\begin{array}{l}{[70.94,} \\
142.67]\end{array}$ \\
\hline
\end{tabular}


When lizards oriented to one stimulus first and then to another, the probability of orientation showed a main effect of motor pattern type, $F(2,5)=3.306, p=.048, \mu^{2}=0.706$; however, there was no main effect of wind condition, $F(2,5)=0.235, p=.797, \mu^{2}=0.074$, or an interaction between these two factors, $F(2,4)=1.009, p=.620, \mu^{2}=0.795$. Pairwise comparison showed significant differences in double orientation probability for responding to one signal before another between TF-PUBR, TF-SAW, and PUBR-SAW pairs during calm conditions (Table 5). During typical wind conditions, there was a significant pairwise comparison between signals in PUBR-SAW pairs (Table 5). For windy conditions, there were significant pairwise comparisons shown in double orientation responses during TF-PUBR and PUBR-SAW pairings (Table 5). Individuals continued to show that they would respond to TFs before PUBRs in TFPUBRs pairings and TFs before SAWs in TF-SAW pairings in calm conditions. Although this was not shown during trials for typical conditions, individuals responded significantly more often to TFs before PUBRs during simulated windy conditions. For PUBR-SAW pairings, conspicuousness to motor pattern order was consistent. During simulated calm, typical, and windy conditions, lizards responded significantly more to PUBRs before SAWs (Figure 7a; Table 6). Additional post-hoc tests showed that response patterns did not vary as wind condition increased $(p>.05)$. Lizards oriented faster to TFs before PUBRs, to TFs before SAWs, and PUBRs before SAWs across all wind conditions $(p<.05)$.

Similar to single response latency results, double orientation when lizards responded to both stimuli showed no main effect of display, $F(2,5)=0.011, p=.897, \mu^{2}=0.012$, wind, $F(2,5)=0.064, p=.938, \mu^{2}$ $=0.007$, or an interaction between these factors, $F(2,4)=0.475, p=.766, \mu^{2}=0.092$. No pairwise comparisons were shown to be significant (Table 5), while descriptive analyses did not reveal any faster response latencies to one signal before another across all wind conditions (Figure 7B; Table 6). However, post-hoc analysis showed that lizards once again responded faster to TFs compared to SAWs in typical conditions $(p<.05)$. Lizards also responded faster to PUBRs compared to SAWs in typical, and faster to PUBRs than to SAWs in windy conditions $(p<.05)$. All other comparisons were not significant $(p>.05)$.

\section{Side Biases}

Results showed no main effect of wind condition, display type, directional orientation, or interaction (Table 7) among these factors regarding the probability of orientation (Figure 8a) or latency to respond (Figure $8 b$ ). No additional significant interactions were found for initial side bias for the probability of orientation and latency to respond (Table 7). Post-hoc analysis revealed no significant pairwise comparisons $(p>.05)$.

\section{Discussion}

Lizards found a particular social signal more conspicuous in a simulated competitive situation of opposing pairs. Phase 1 showed that signal salience is consistently ordered from the tail-flick (attention), push-up body rock (aggressive), and slow arm wave (submissive). As was shown in Phase 2, the same hierarchical trend was evident across varying wind conditions (calm, typical, and windy). Comparisons between initial and secondary orientation for probability of orientation and latency across phases showed the same salience order of signals. Differences among the motor patterns in conspicuousness are hence both consistent with different measurement techniques and robust across a range of environmental conditions. However, both phases showed no significant difference in side bias orientation in similar or varying wind, suggesting no lateralized function. 
Figure 7

Response to Display Pairs Over Signal Pairs (M \pm SEM) Across All Wind Conditions During Double Orientation Responses During Phase 2: a) Proportion and b) Latency

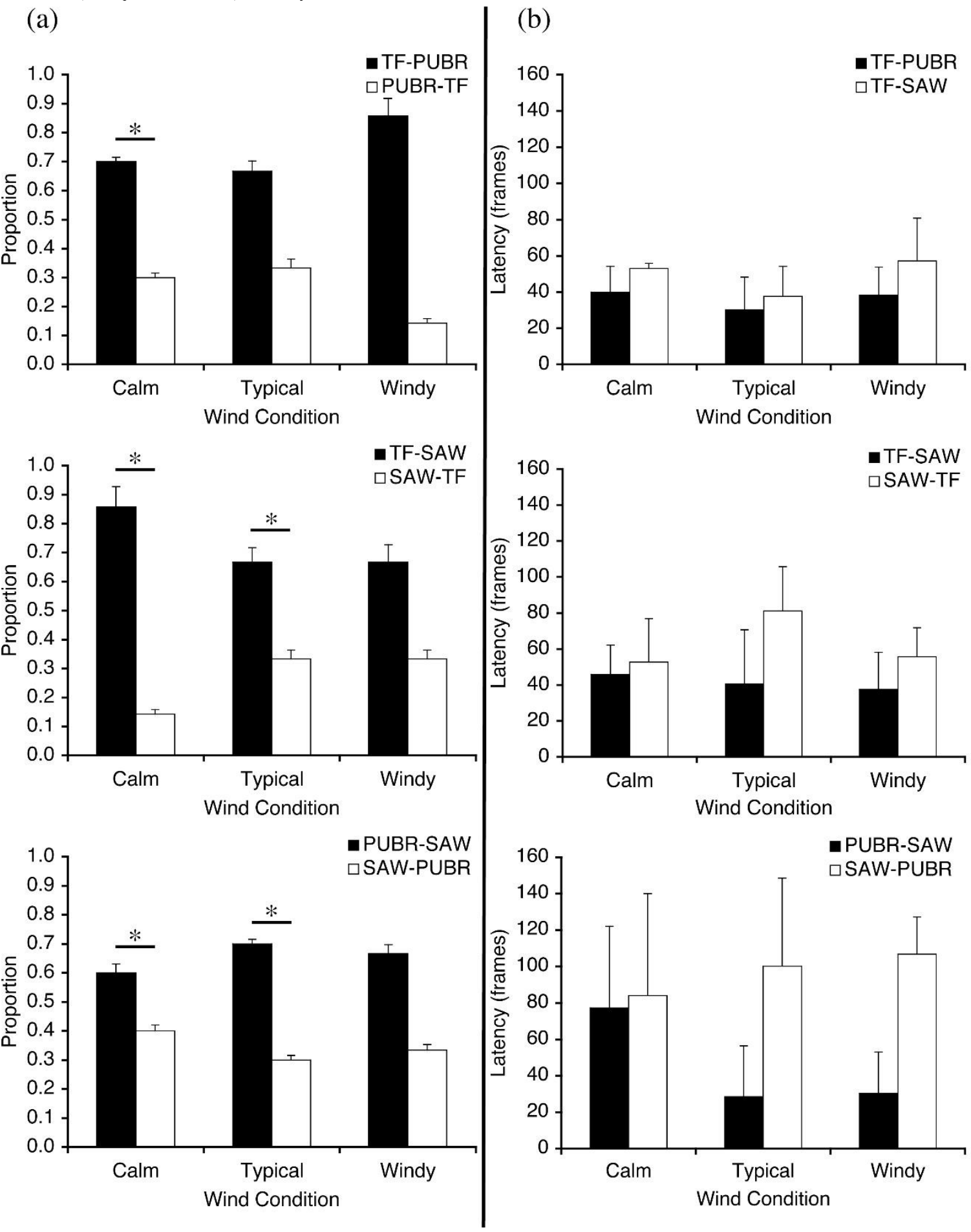

Note. * indicates a significant difference between display pairs $(p<.05)$. The descriptive order (e.g., TF-PUBR vs. PUBR-TF) refers to the order in which individuals oriented to the monitor with the first display, followed by orientation to the second display on the opposite monitor. 
Figure 8

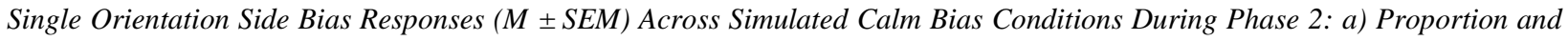
b) Latency
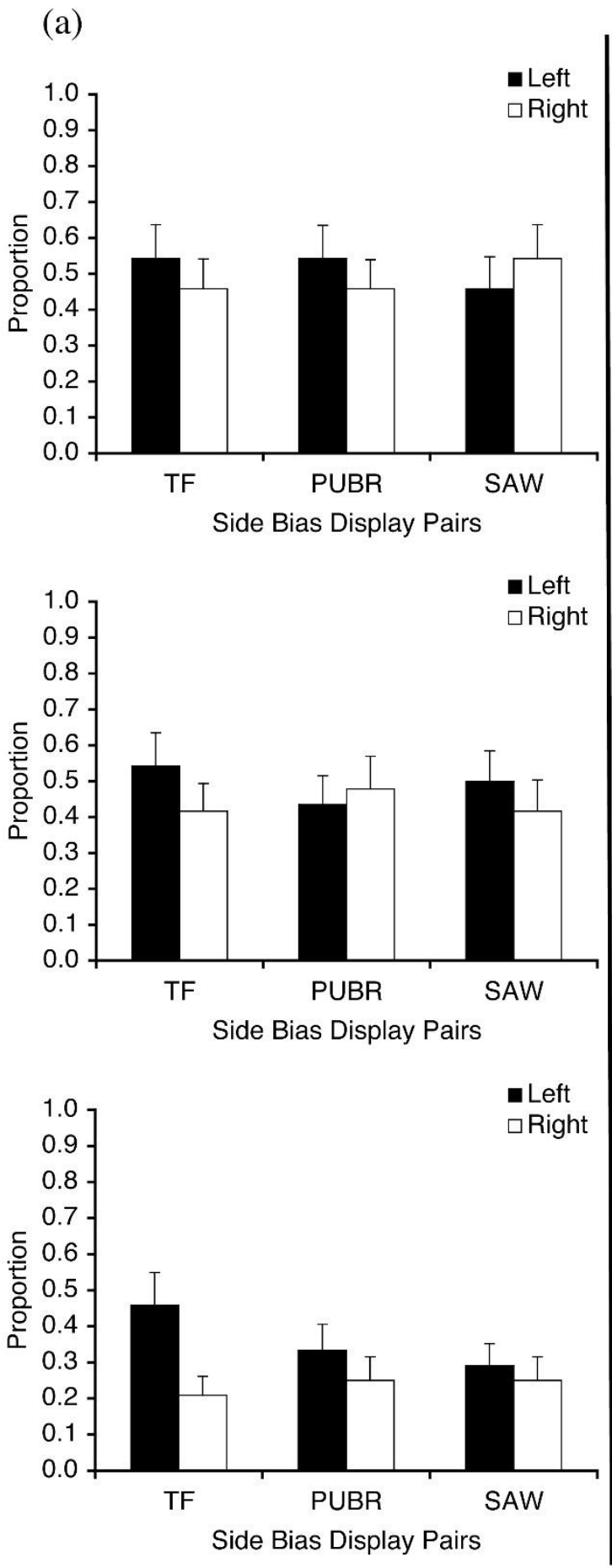

(b)
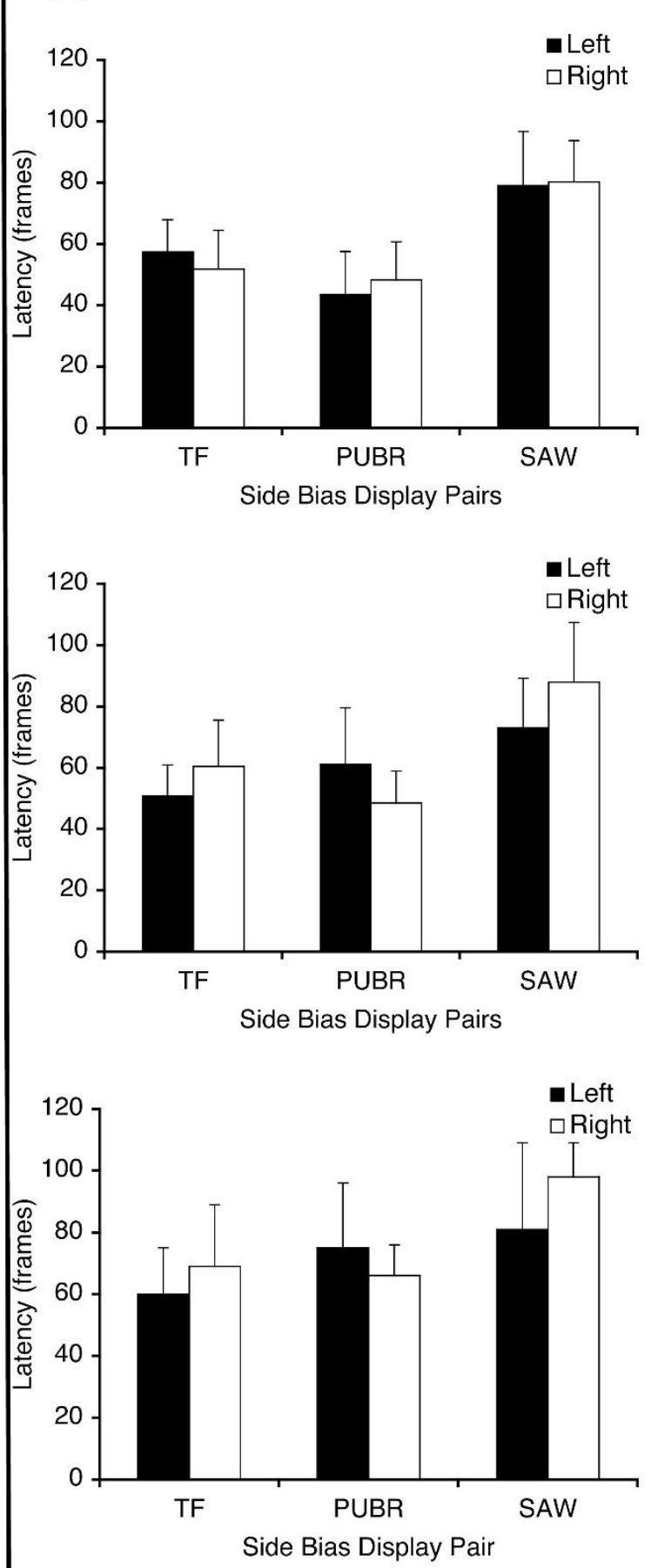
Table 7

Phase 2: Main Effects and Interactions for Side Bias Responses for Single Orientation for Probability of Orientation and Latency to Response

\begin{tabular}{|c|c|c|c|c|c|c|c|c|}
\hline \multirow{3}{*}{ Measure } & \multicolumn{8}{|c|}{ Initial } \\
\hline & \multicolumn{4}{|c|}{ Orientation } & \multicolumn{4}{|c|}{ Latency } \\
\hline & $F$ & $d f$ & $p$ & $\mu^{2}$ & $F$ & $d f$ & $p$ & $\mu^{2}$ \\
\hline Wind & 0.48 & 2,5 & .63 & 0.07 & 1.05 & 2,5 & .38 & 0.02 \\
\hline Display & 1.61 & 2,5 & .22 & 0.20 & 3.10 & 2,5 & .055 & 0.06 \\
\hline Direction & 1.70 & 1,5 & .40 & 0.92 & 1.22 & 1,5 & .28 & 0.06 \\
\hline Wind*Display & 0.48 & 2,4 & .75 & 0.11 & 0.31 & 2,4 & .96 & 0.01 \\
\hline Wind*Direction & 0.16 & 2,10 & .83 & 0.28 & 0.80 & 2,10 & .72 & 0.07 \\
\hline Display*Direction & 0.85 & 2,10 & .59 & 0.38 & 1.31 & 2,10 & .17 & 0.11 \\
\hline Wind*Display*Direction & 1.10 & 2,13 & .37 & 0.12 & 1.10 & 2,13 & .21 & 0.14 \\
\hline
\end{tabular}

\section{Signal Efficacy and Relative Conspicuousness}

The clear directional responses to competing signal pair combinations identified the relative salience of visual displays. The order of signal importance was observed when individuals oriented towards tail-flicks in TF-PUBR pairs, tail-flicks in TF-SAW pairs, and push-up body rocks in PUBR-SAW pairs. Hierarchical responses likely identify attention-seeking (assertion) displays as recruiting the greatest level of orientation, followed by aggressive (challenge) signals, and lastly submissive displays.

The results support previous studies that have identified the intent and classification of social signals in the jacky dragon. In the earlier stages of development for the lizard animation, Peters and Evans (2003b) created a computer-generated jacky dragon tail that was independent of the entire body and shown to live individuals. While manipulating various motion attributes, Peters and Evans (2003b) found that the duration of the tail flick was the most efficacious characteristic compared to speed, acceleration, and temporal patterns of display. Inherently, assertion signals (Fleishman 1988b; Jenssen, 1977) initiate possible interactions by broadcasting into the environment rather than to an identified receiver nearby. If a receiver chooses to acknowledge and respond to these initial signals, then this reciprocation may escalate into a contest (Langemann et al., 2000). Assertion signals may be particularly important because they serve two functions. First, the signaler may produce a broadcast display to all possible neighboring receivers as to alert conspecifics of their presence (Zucker, 1994). Second, receivers may then choose to engage with the signaler in competing for resources, acknowledge the presence of the signaler and respond submissively, or ignore the signal altogether (Parker, 1974). Tail-flicks are broadcast independently or presented as the first signal during the entire sequence of a display action pattern (Peters \& Ord, 2003). The tail-flick has the largest sweep area (Peters \& Evans, 2003a, 2003b) and the fastest speed-time profile (Woo et al., 2017) compared to other signals, which supports its design for the efficient recruitment of initial responses from other conspecifics.

Challenge displays, such as the push-up body rock, may require a longer period for a response. Such displays contain social information about the signaler, and thus possibly require a higher level of cognitive assessment before any physical movement to respond. Incidentally, the push-up body rock in jacky dragons is also an effective challenge display, but is more energetically demanding to produce and 
possesses different motion characteristics. Woo and Rieucau (2012) examined signal efficacy of the pushup body rock by manipulating both the frequency and speed of the display and by also employing the use of a computer animated lizard. In staged interactions between live individuals and the animated lizard, they found that while duration was important for efficacy, realistic displays are likely constrained by the limit of consecutive push-up body rocks. For a challenge signal, this constraint of signal design is a likely important tradeoff between energetic demands in motor pattern production and the success in a potential forthcoming physical contest. In another analogous example from the sagebrush lizard (Scelorperus graciosus), the push-up display serves as an aggressive signal to display vigor, as well as the intention to compete for resources (Martins, 1993, 1994). Similarly, in Anolis lizards, challenges to potential resources, such as territories or mating partners, involve an energetically demanding head-bob display (Decourcy \& Jenssen, 1994). The responses to challenge displays are an indicator of dominance during territorial disputes (Radder et al., 2006) and a potential catalyst for male-male competition (Bertram, 2004; Schuett \& Duvall, 1996).

The submissive signal is probably the least threatening display during a competitive situation. Appeasement signals are designed to reduce the level of aggressive behavior during interactions as well as reducing the risk of potential harm inflicted upon the subordinate individual (Barlow, 1970; Dixon, 1949; Simpson, 1968). In comparison to alerting and aggressive signals, the slow arm wave functions as the jacky dragon's submissive and appeasement display. In an earlier playback study of visual signals, Ord and Evans (2002) employed an interactive technique where live jacky dragons were shown interactive and noninteractive digital video. The interactive sequences were digitally altered videos of males producing aggressive (push-up body rocks) and appeasement (slow arm wave) displays that could be engaged during staged contests. Their results demonstrated the usefulness of interactive playback design as a tool for studying visual communication, and also showed how both aggressive and submissive signals can be elicited from the perception of threat or dominance (Ord \& Evans, 2002). In the competitive situations that were staged during my phases, the presentation of the slow arm wave was paired with either an assertive or aggressive display, except during side bias trials. Individuals that choose to initiate or respond with a submissive signal should pose no threat to the immediate individual or resource holder. Unless the intentions of the submissive individual are dishonest, and they use the signal to gain closer access to their opponent, there is no immediate threat to the initial signaler (Johnstone, 1996).

In my trials, the bystander is eavesdropping on the interaction between two individuals that are displaying. Eavesdropping allows individuals to assess the current situation as well as collect information about the two signalers and how the receiver may or may not benefit from joining the interaction (Dabelsteen et al., 1997). For example, green swordtails (Xiphophorus halleri) were allowed to witness a contest between two conspecifics and were subsequently paired in a staged encounter with either the winner or loser (Early \& Dugatkin, 2002). Results from these interactions suggested that bystanders who were exposed to such contests may choose to retain information gathered about other individuals and react indifferently (Early \& Dugatkin, 2002). Furthermore, the escalation of a contest did not seem to alter the bystander's behavior, and they did not act more aggressively to either winners or losers of a contest (Earley et al., 2005). In contrast, eavesdropping may allow bystanders to observe an altercation and learn about competing individuals based on the outcomes. In the northern paper wasp (Polistes fuscatus), bystander nest-founding queens alter their behavioral interactions based on social observations of fighting conspecifics, ultimately behaving less aggressively to individuals that were identified as highly aggressive fighters (Tibbetts et al., 2020). Here, jacky lizards clearly showed an orientation preference towards aggressive behavior but did not initiate an interaction with either simulated opponent, which is possibly due to the lack of consecutive displays by the animation that are necessary for any form of social assessment (Ord \& Evans, 2002; Van Dyk \& Evans, 2007).

\section{Signal Salience Order Against Variations of Natural Wind Condition}

Despite the variation in the movement of windblown vegetation, all signals were robust (i.e., continued to evoke responses above chance) and maintained relative saliency. This is consistent with 
previous studies that have examined signal saliency (Peters et al., 2008; Woo \& Rieucau, 2013). Fleishman (1986) has suggested that there are two mechanisms by which lizards are able to extract salient motion from the noise generated by windblown vegetation: 1) sensory systems have evolved to respond to selective conspicuous movement, and 2) individuals experience short-term habituation to the current movement of vegetation, which increases the sensitivity to motion outside the current visual field occurs. Apparent motion patterns outside the current motion of noise are thus a critical feature for signal conspicuousness (Peters \& Davis, 2006).

Signals are designed to overcome the masking effect of visual noise. In the visual system of lizards, there seems to be two strategies. Anolis lizards can discriminate salient signals within complex habitat and speed up head bobbing displays when moving vegetation increases due to wind force (Ord et al., 2007). However, jacky lizards may gauge microhabitat changes and increase the duration of their displays to be more conspicuous, as wind force increases (Peters et al., 2007).

Although this study imposed specific constraints on signal detection distance, there is a likelihood that displays may broadcast over greater distances, and thus may also interact with aspects of the physical environment that were not tested here. Bian et al. (2018) devised a technologically eloquent study where they created artificial, yet realistic environments where they could further control visual aspects of depth perception, angle and orientation of display, wind conditions, and light conditions. Based on the current understanding of signal efficacy in staged natural and artificial environmental conditions, Bian et al. (2019) further tested the efficacy of the same A. muricatus social displays and found that increasing wind condition and lower luminance decreased signal efficacy to the point where detection was negligible. Here, both the current study and those by Bian et al. $(2018,2019)$ further elucidate the constraints on signal design and efficacy as shaped by the physical environment.

\section{No Evidence of Side Biases}

I found no evidence in Phase 1 or Phase 2 to suggest that there was any side bias in signal detection and orientation to assertive, aggressive, or submissive signals. Signals that were presented during test trials simulated aggressive and appeasement encounters, providing subjects with two rival scenarios.

Origins of the aggressive responsiveness have been mediated by neural control of the amygdala and hypothalamic region in fish (Bisazza \& de Santi, 2003). For Anolis lizards in particular, the physiological responses attributed to reciprocation between aggressive and submissive signals as a function of lateralization share very similar neural pathways (Baxter, 2001; Baxter, Ackermann, et al., 2001; Baxter, Clark, et al., 2001). However, the absence of possible lateralized function in Jacky lizards is further supported by similar indifferent responses that were found when they were shown frontal and orthogonal orientation video stimuli (Peters \& Evans, 2007).

Jacky lizards do not show any particular lateralized bias for either aggressive or submissive signaling to suggest any clear hemispherical mediation of these responses. However, the benefit for nondiscriminatory side bias allows for all salient motion to be conspicuous, as well as no bias for having to orient to a predator with one particular side, and then fleeing from danger. Unlike species that produce lateralized behavior in both processing and production of displays, jacky dragons appear to have no specific lateralization of displays, and this also appears to produce no immediate benefit or detriment to survival. Woo and Rieucau (2008) had found previously that there was no preference in forelimb usage for slow arm wave displays, even though the movement of the display was sometimes masked by the body of the animal. Here, I have only measured the peripheral sensitivity to movement, and this may require longer display presentation beyond the perceptual level to test cognitive attributes necessary for opponent assessment.

\section{Conclusion}

The most salient signal in the Jacky dragon repertoire is the tail-flick, followed by the push-up body rock, and lastly the slow arm wave. The hierarchical order of saliency is also stable across increasing wind conditions, despite a slight detriment to actual visibility due to the masking of moving vegetation. 
Additionally, side biases in orientation to display were not found. Signal design in the jacky lizard has thus evolved to first detect assertive broadcast displays before engaging in other signals that may have more functional importance, such as aggressive or submissive displays. This study has further supported signal salience and conspicuousness in the jacky lizard across the range of normal environmental noise; however, further study is warranted for understanding any other potential lateralized biases in signal detection and recognition.

\section{Acknowledgements}

KLW was supported by the SUNY Empire State College Faculty Development Fund, the Centre for the Integrative Study of Animal Behaviour (CISAB) development fund, and the Australian Research Council (DP0345643). I thank Darren Burke (University of Newcastle) and Marie Herberstein (Macquarie University) for useful comments on earlier versions of the manuscript, and Kristy Biolsi (St. Francis College and the Center for the Study of Pinniped Ecology \& Cognition) for comments on subsequent manuscript drafts. I also thank the two anonymous reviewers for their helpful comments and suggestions for improving the paper.

\section{References}

Abaid, N., Spinello, C., Laut, J., \& Porfiri, M. (2012). Zebrafish (Danio rerio) responds to images animated by mathematical models of animal grouping. Behavioural Brain Research, 232(2), 406-410.

Allard, H. A. (1935). Synchronous flashing in fireflies. Science, 82(2135), 517-518.

Allen, J. M., \& Nicoletto, P. F. (1997). Response of Betta splendens to computer animations of males with fins of different length. Copeia, 1997(1), 195-199.

Andersson, M. B. (1994). Sexual selection. Princeton University Press.

Barlow, G. W. (1970). A test of appeasement and arousal hypothesis of courtship behavior in a cichlid fish, Etroplus maculates. Zeitschrift für Tierpsychologie, 27(7), 779-806.

Baube, C. L., Rowland, W. J., \& Fowler, J. B. (1995). The mechanisms of colour-based mate choice in female threespine sticklebacks: Hue, contrast and configurational cues. Behaviour, 132(13-14), 979-996.

Baxter, L. R. Jr (2001). Brain mediation of Anolis social dominance displays: III. Differential forebrain ${ }^{3} \mathrm{H}$-sumatriptan binding to dominant vs. submissive males. Brain, Behavior and Evolution, 57(4), 202-13.

Baxter, L. R. Jr, Ackermann, R. F., Clark, E. C., \& Baxter, J. E. (2001). Brain mediation of Anolis social dominance displays: I. Differential basal ganglia activation. Brain, Behavior and Evolution, 57(4), 169-183.

Baxter, L. R. Jr, Clark, E. C., Ackermann, R. F., Lacan, G., \& Melega, W. P. (2001). Brain mediation of Anolis social dominance displays. Brain, Behavior and Evolution, 57(4), 184-201.

Bertram, S. M. (2004). Temporal shifts in conspicuousness: Mate attraction displays of the Texas field cricket, Gryllus texensis. Ethology, 110(12), 963-975.

Bian, X., Chandler, T., Laird, W., Pinilla, A., \& Peters, R. (2018). Integrating evolutionary biology with digital arts to quantify ecological constraints on vision-based behaviour. Methods in Ecology and Evolution, 9(3), 544559.

Bian, X., Chandler, T., Pinilla, A., \& Peters, R. A. (2019). Now you see me, now you don't: Environmental conditions, signaler behavior, and receiver response thresholds interact to determine the efficacy of a movement-based animal signal. Frontiers in Ecology and Evolution, 7, 130.

Bisazza, A., \& de Santi, A. (2003). Lateralization of aggression in fish. Behavioural Brain Research, 141(2), 131-136.

Bosch, J., Rand, A. S., \& Ryan, M. J. (2000). Acoustic competition in Physalaemus pustulosus, a differential response to calls of relative frequency. Ethology, 106(10), 865-871.

Brémond, J-C. (1978). Acoustic competition between the song of the wren (Troglodytes troglodytes) and the songs of other species. Behaviour, 65(1-2), 89-98.

Buck, J. (1938). Synchronous rhythmic flashing of fireflies. Quarterly Review of Biology, 13(3), 301-314.

Buck, J. (1988). Synchronous rhythmic flashing of fireflies II. Quarterly Review of Biology, 63(3), 265-289.

Cantalupo, C., Bisazza, A., \& Vallortigara, G. (1996). Lateralization of displays during aggressive and courtship behaviour in the Siamese fighting fish (Betta splendens). Physiology \& Behavior, 60(1), 249-252.

Cardoso, J. C. F., \& dos Santos Mendonça, J. (2019). The trade-off between fleeing and tonic immobility behaviors in an ectothermic animal. Acta Ethologica, 22(2), 129-134. 
Carpenter, C. C. Badham, J. A., \& Kimble, B. (1970). Behavior patterns of three species of Amphibolurus (Agamidae). Copeia, 1970(3), 497-505.

Carpenter, C. C., \& Ferguson, G. W. (1977). Variation and evolution of stereotyped behavior in reptiles. In C. Gans \& D. W. Tinkle (Eds.), Biology of the reptilia (pp. 335-554). Academic Press.

Chouinard-Thuly, L., Gierszewski, S., Rosenthal, G. G., Reader, S., Rieucau, G., Woo, K. L., Gerlai, R., Tedore, C., Ingley, S. J., Stowers, J., Frommen, J. G., Troje, N. F., Dolins, F. L., \& Witte, K. (2017). Technical and conceptual question of using virtual stimuli in animal behavior research. Current Zoology, 63(1), 5-19.

Dabelsteen, T., McGregor, P. K., Holland, J., Tobias, J. A., \& Pedersen, S. B. (1997). The signal function of overlapping singing in male robins. Animal Behaviour, 53(2), 249-256.

Deckel, A. W. (1995). Laterality of aggressive responses in Anolis. Journal of Experimental Zoology, 272(3), 194200.

DeCourcy, K. R., \& Jenssen, T. A. (1994). Structure and use of male territorial headbob signals by the lizard, Anolis carolinensis. Animal Behaviour, 47(2), 251-262.

Dixon, K. L. (1949). Behavior of the plain titmouse. Condor, 51(3), 110-136.

Earley, R. L., Druen, M. Dugatkin, L. A. (2005). Watching fights does not alter a bystander's response towards naïve conspecific in male green swordtail fish, Xiphophorus halleri. Animal Behaviour, 69(5), 1139-1145.

Fleishman, L. J. (1986). Motion detection in the presence and absence of background motion in an Anolis lizard. Journal of Comparative Physiology A, 159(5), 711-720.

Fleishman, L. J. (1988a). Sensory and environmental influences on display form in Anolis auratus, a grass anole from Panama. Behavioral Ecology and Sociobiology, 22(5), 309-316.

Fleishman, L. J. (1988b). Sensory influences on physical design of a visual display. Animal Behaviour, 36(5), 14201424.

Fleishman, L. J. (1992). The influence of the sensory system and the environment on motion patterns in the visual displays of anoline lizards and other vertebrates. American Naturalist, 139(1992), S36-S61.

Fleishman, L. J., \& Persons, M. (2001). The influence of stimulus and background colour on signal visibility in the lizard Anolis cristatellus. Journal of Experimental Biology, 204(9), 1559-1575.

Fox, N. A. (1991). If it's not left, it's right: Electroencephalograph asymmetry and the development of emotion. American Psychologist, 46(8), 863-872.

Gatesy, S. M., Middleton, K. M., Jenkins, F. A., \& Shubin, N. H. (1999). Three-dimensional preservation of foot movements in Triassic theropod dinosaurs. Nature, 399(6732), 141-144.

Gerhardt, H. C., \& Klump, G. M. (1988). Masking of acoustic signals by the chorus background noise in the green tree frog: A limitation on mate choice. Animal Behaviour, 36(3), 1247-1249.

Gibbons, J. R. H. (1979). The hind leg pushup display of the Amphibolurus decresii species complex (Lacertilia: Amagidae). Copeia, 1979(1), 29-40.

Gierszewski, S., Baker, D., Müller, K., Hütwohl, J. M., Kuhnert, K. D., \& Witte, K. (2018). Using the FishSim animation toolchain to investigate fish behavior: A case study on mate-choice copying in Sailfin Mollies. Journal of Visualized Experiments, 141, e58435.

Gierszewski, S., Müller, K., Smielik, I., Hütwohl, J. M., Kuhnert, K. D., \& Witte, K. (2017). The virtual lover: Variable and easily guided 3D fish animations as an innovative tool in mate-choice experiments with sailfin molliesII. Validation. Current Zoology, 63(1), 65-74.

Götz, T., \& Janik, V. M. (2011). Repeated elicitation of the acoustic startle reflex leads to sensitisation in subsequent avoidance behaviour and induces fear conditioning. BMC Neuroscience, 12(1), 30.

Greenfield, M. D. (1983). Unsynchronized chorusing in the conehead katydid Neoconocephalus affinis (Beauvois). Animal Behaviour, 31(1), 102-112.

Greenfield, M. D. (1994a). Cooperation and conflict in the evolution of signal interactions. Annual Review of Ecology and Systematics, 25(1), 97-126.

Greenfield, M. D. (1994b). Synchronous and alternating choruses in insects and anurans: Common mechanisms and diverse functions. American Zoologist, 34(6), 605-615.

Harlow, P. S., \& Taylor, J. E. (2000). Reproductive ecology of the Jacky dragon (Amphibolurus muricatus): An agamid lizard with temperature-dependent sex determination. Austral Ecology, 25(6), 640-652.

Hayes, A. F., \& Preacher, K. J. (2014). Statistical mediation analysis with a multicategorical independent variable. British Journal of Mathematical and Statistical Psychology, 67(3), 451-470.

Hoffman, A. M., Robakiewicz, P. E., Tuttle, E. M., \& Rogers, L. J. (2006). Behavioural laterlisation in the Australian magpie (Gymnorhina tibicen). Laterality, 11(2), 110-121.

Jenssen, T. A., Decourcy, K. R., \& Congdon, J. D. (2005). Assessment in contests of male lizards (Anolis carolinensis): How should smaller males respond when size matters? Animal Behaviour, 69(6), 1325-1336. 
Johnstone, R. A. (1996). Multiple displays in animal communication: 'Backup signals' and 'multiple messages.' Philosophical Transactions of the Royal Society of London, Series B, 351(1337), 329-338.

Lindemann-Biolsi, K. L., \& Reichmuth, C. (2014). Cross-modal transitivity in a California sea lion (Zalophus californianus). Animal Cognition, 17(4), 879-890.

Llewellyn, D., Brown, G. P., Thompson, M. B., \& Shine, R. (2011). Behavioral responses to immune-system activation in an anuran (the cane toad, Bufo marinus): Field and laboratory studies. Physiological and Biochemical Zoology, 84(1), 77-86.

López, P., Martín, J., \& Cuadrado, M. (2004). The role of lateral blue spots in intrasexual relationships between male Iberian rock-lizards, Lacerta monticola. Ethology, 110(7), 543-561.

Martins, E. P. (1993). Contextual use of the push-up display by the sagebrush lizard, Sceloporus graciosus. Animal Behaviour, 45(1), 25-36.

Martins, E. P. (1994). Structural complexity in a lizard communication system: The Sceloporus graciosus "push-up" display. Copeia, 1994(4), 944-955.

Martin, R. A., \& Melfi, V. (2016). A comparison of zoo animal behavior in the presence of familiar and unfamiliar people. Journal of Applied Animal Welfare Science, 19(3), 234-244.

Marx, J. L. (1983). The two sides of the brain. Science, 220(4596), 488-490.

Marzona, E., \& Giacoma, C. (2002). Display lateralization in the courtship behaviour of the alpine newt (Triturus alpestris). Laterality, 7(3), 285-295.

Miklósi, A., Andrew, R. J., \& Savage, H. (1998). Behavioural lateralization of the tetrapod type in the zebrafish (Brachydanio rerio). Physiology \& Behaviour, 63(1), 127-135.

Minckley, R. L., Greenfield, M. D., \& Tourtellot, M. K. (1995). Chorus structure in tarbrush grasshoppers: Inhibition, selective phonoresponse, and signal competition. Animal Behaviour, 50(3), 579-594.

Morrison, T. F. (1929). Observation on the synchronous flashing of fireflies in Siam. Science, 69(1789), 400-401.

Müller, K., Smielik, I., Hütwohl, J. M., Gierszewski, S., Witte, K., \& Kuhnert, K. D. (2017). The virtual lover: Variable and easily guided 3D fish animations as an innovative tool in mate-choice experiments with sailfin molliesI. Design and implementation. Current Zoology, 63(1), 55-64.

O’Connor, K. I., Metcalfe, N. B., \& Taylor, A. C. (1999). Does darkening signal submission in territorial contests between juvenile Atlantic salmon, Salmo salar? Animal Behaviour, 58(6), 1269-1276.

Ord, T. J., Blumstein, D. T., \& Evans, C. S. (2002). Ecology and signal evolution in lizards. Biological Journal of the Linnean Society, 77(1), 127-148.

Ord, T. J., \& Evans, C. S. (2002). Interactive video playback and opponent assessment in lizards. Behavioural Processes, 59(2), 55-65.

Ord, T. J., Peters, R. A., Evans, C. S., \& Taylor, A. J. (2002). Digital video playback and visual communication in lizards. Animal Behaviour, 63(5), 879-890.

Ord, T. J., Peters, R. A., Clucas, B., \& Stamps, J. A. (2007). Lizards speed up visual displays in noisy motion habitats. Proceedings of the Royal Society B: Biological Sciences, 274(1613), 1057-1062.

Parker, G. A. (1974). Assessment strategy and the evolution of fighting behaviour. Journal of Theoretical Biology, 47(1), 223-243.

Peake, T. M. (2005). Eavesdropping in communication networks. In P. McGregor (Ed.), Animal communication networks (pp. 13-37). Cambridge University Press.

Persons, M. H., Fleishman, L. J., Frye, M. A., \& Stimphil, M. E. (1999). Sensory response patterns and the evolution of visual signal design in anoline lizards. Journal of Comparative Physiology A, 184(6), 585-607.

Peters, R. A. (2013). Noise in visual communication: Motion from wind-blown plants. In H. Brumm (Ed.), Animal communication and noise (pp. 311-330). Springer.

Peters, R. A., \& Allen, S. J. (2009). Movement signal choreography unaffected by receiver distance in the Australian Jacky lizard, Amphibolurus muricatus. Behavioral Ecology and Sociobiology, 63(11), 1593-1602.

Peters, R. A., \& Evans, C. S. (2003a). Design of the Jacky dragon visual display: Signal and noise characteristics in a complex moving environment. Journal of Comparative Physiology A, 189(6), 447-459.

Peters, R. A., \& Evans, C. S. (2003b). Introductory tail-flick of the Jacky dragon visual display: Signal efficacy depends upon duration. Journal of Experimental Biology, 206(23), 4293-4307.

Peters, R. A., \& Evans, C. S. (2007). Active space of a movement-based signal: Response to the Jacky dragon (Amphibolurus muricatus) display is sensitive to distance, but independent of orientation. Journal of Experimental Biology, 210(3), 395-402.

Peters, R. A., \& Ord, T. J. (2003). Display of the Jacky dragon, Amphibolurus muricatus, (Lacertilia: Agamidae), to intruders: A semi-Markovian process. Austral Ecology, 28(5), 499-506. 
Peters, R., Hemmi, J., \& Zeil, J. (2008). Image motion environments: Background noise for movement-based animal signals. Journal of Comparative Physiology A, 194(5), 441-456.

Qin, M., Wong, A., Seguin, D., \& Gerlai, R. (2014). Induction of social behavior in zebrafish: Live versus computer animated fish as stimuli. Zebrafish, 11(3), 185-197.

Radder, R. S., Saidapur, S. K., Shine, R., \& Shanbhag, B. A. (2006). The language of lizards: Interpreting the function of visual displays of the Indian rock lizard, Psammophilus dorsalis (Agamidae). Journal of Ethology, 24(3), 275-283.

Roberts, N. S., McCaulley, C., \& Mendelson, T. C. (2019). Validating the use of computer animations in male Etheostoma zonale: A comparison of individual response to live and artificial stimuli. Current Zoology, 65(6), 725-727.

Rogers, L. J., \& Kaplan, G. (1996). Hand preferences and other lateral biases in rehabilitated orang-utans, Pongo pygmaeus pygmaeus. Animal Behaviour, 51(1), 13-25.

Rowland, W. J., Bolyard, K. J., \& Halpern, A. D. (1995). The dual effect of stickleback nuptial coloration on rivals: Manipulation of a graded signal using video playback. Animal Behaviour, 50(1), 267-272.

Ryan, M. J. (1986). Factors influencing the evolution of acoustic communication: Biological constraints. Brain, Behavior, and Evolution, 28(1-3), 70-82.

Schuett, G. W., \& Duvall, D. (1996). Head lifting by female copperheads, Agkistrodon contorix, during courtship: Potential mate choice. Animal Behaviour, 51(2), 367-373.

Simpson, M. J. A. (1968). The display of the Siamese fighting fish, Betta splendens. Animal Behaviour Monographs, $1(1), 1-75$.

Sovrano, V. A. (2004). Visual lateralization in response to familiar and unfamiliar stimuli in fish. Behavioural Brain Research, 152(2), 385-391.

Stirman, J. N., Townsend, L. B., \& Smith, S. L. (2016). A touchscreen based global motion perception task for mice. Vision Research, 127(1), 74-83.

Tallarovic, S. K., \& Zakon, H. H. (2005). Electric organ discharge frequency jamming during social interactions in brown ghost knifefish, Apteronotus leptoryhnchus. Animal Behaviour, 70(6), 1355-1365.

Tarof, S. A., Dunn, P. O., \& Whittingham, L. A. (2005). Dual functions of a melanin-based ornament in the common yellowthroat. Proceedings of the Royal Society of London Series B, 272(1568), 1121-1127.

Tedore, C., \& Johnsen, S. (2013). Pheromones exert top-down effects on visual recognition in the jumping spider Lyssomanes viridis. Journal of Experimental Biology, 216(9), 1744-1756.

Tedore, C., \& Johnsen, S. (2015). Visual mutual assessment of size in male Lyssomanes viridis jumping spider contests. Behavioral Ecology, 26(2), 510-518.

Thorson, R. F., \& Fine, M. L. (2002). Acoustic competition in the gulf toadfish Opsanus beta: Acoustic tagging. Journal of the Acoustical Society of America, 111(5), 2302-2307.

Tibbetts, E. A., Wong, E., \& Bonello, S. (2020). Wasps use social eavesdropping to learn about individual rivals. Current Biology, 30(15), 3007-3010.

Ulanovsky, N., \& Fenton, M. B., Tsoar, A., \& Korine, C. (2004). Dynamics of jamming avoidance in echolocating bats. Proceedings of the Royal Society London B, 271(1547), 1467-1475.

Vaicekauskaite, R., Schneider, J. N., \& Delfour, F. (2019). Does enrichment improve well being in animals under human care? A case study of two harbor seals (Phoca vitulina). Journal of Applied Animal Welfare Science, 22(3), 255-266.

Van Dyk, D. A., \& Evans, C. S. (2007). Familiar-unfamiliar discrimination based on visual cues in the Jacky dragon, Amphibolurus muricatus. Animal Behaviour, 74(1), 33-44.

Ware, E. L., Saunders, D. R., \& Troje, N. F. (2017). Social interactivity in pigeon courtship behavior. Current Zoology, 63(1), 85-95.

Watanabe, S., \& Troje, N. F. (2006). Towards a "virtual pigeon": A new technique for investigating avian social perception. Animal Cognition, 9(4), 271-279.

Woo, K. L., \& Burke, D. (2008). Technique for measuring speed and visual motion sensitivity in lizards. Psicológica, 29(2), 135-151.

Woo, K. L., Burke, D., \& Peters, R. A. (2009). Motion sensitivity in lizards: Random-dot kinematograms reveal the importance of motion noise for signal detection. Animal Behaviour, 77(2), 307-315.

Woo, K. L. (2007). Computer-generated animal model stimuli. Journal of Visualized Experiments, 6, 243.

Woo, K. L., \& Rieucau, G. (2008). Considerations in video playback design: Using optic flow analysis to examine motion characteristics of live and computer-generated animation sequences. Behavioural Processes, 78(3), 455-463. 
Woo, K. L., \& Rieucau, G. (2011). From dummies to computer-animated stimuli: A review of computer-animated stimuli used in animal behavior studies. Behavioral Ecology \& Sociobiology, 65(9), 1671-1685.

Woo, K. L., \& Rieucau, G. (2012). Aggressive signal design in the Jacky dragon (Amphibolurus muricatus): Display duration affects efficiency. Ethology, 118(2), 157-168.

Woo, K. L., \& Rieucau, G. (2013). Efficiency of aggressive and submissive visual displays against environmental motion noise in the Jacky dragon (Amphibolurus muricatus). Ethology, Ecology, \& Evolution, 25(1), 82-94.

Woo, K. L., \& Rieucau, G. (2015). The importance of syntax in a dynamic visual signal: Recognition of Jacky dragon threat displays depends upon sequence. Acta Ethologica, 18(3), 255-263.

Woo, K. L., Rieucau, G., \& Burke, D. (2017). Computer-animated stimuli to measure motion sensitivity for ecological contexts: Constraints on signal design in the Jacky dragon. Current Zoology, 63(1), 75-84.

Zucker, N. (1994). Social influence on the use of a modifiable status signal. Animal Behaviour, 48(6), 1317-1324. 